\title{
Synaptogenesis of the Calyx of Held: Rapid Onset of Function and One-to-One Morphological Innervation
}

\author{
Brian K. Hoffpauir, Janelle L. Grimes, Peter H. Mathers, and George A. Spirou \\ Sensory Neuroscience Research Center, Department of Otolaryngology, West Virginia University School of Medicine, Morgantown, West Virginia 26506- \\ 9303
}

Synaptogenesis during early development is thought to follow a canonical program whereby synapses increase rapidly in number and individual axons multiply-innervate nearby targets. Typically, a subset of inputs then out-competes all others through experience-driven processes to establish stable, long-lasting contacts. We investigated the formation of the calyx of Held, probably the largest nerve terminal in the mammalian CNS. Many basic functional and morphological features of calyx growth have not been studied previously, including whether mono-innervation, a hallmark of this system in adult animals, is established early in development. Evoked postsynaptic currents, recorded from neonatal mice between postnatal day 1 (P1) and P4, increased dramatically from $-0.14 \pm 0.04 \mathrm{nA}$ at P1 to $-6.71 \pm$ $0.65 \mathrm{nA}$ at P4 with sharp jumps between P2 and P4. These are the first functional assays of these nascent synapses for ages less than P3. AMPA and NMDA receptor-mediated currents were prominent across this age range. Electron microscopy (EM) revealed a concomitant increase, beginning at P2, in the prevalence of postsynaptic densities (16-fold) and adhering contacts (73-fold) by P4. Therefore, both functional and structural data showed that young calyces could form within $2 \mathrm{~d}$, well before the onset of hearing around P8. Convergence of developing calyces onto postsynaptic targets, indicative of competitive processes that precede mono-innervation, was rare (4 of 29) at P4 as assessed using minimal stimulation electrophysiology protocols. Serial EM sectioning through 19 P4 cells further established the paucity ( 2 of 19) of convergence. These data indicate that calyces of Held follow a noncanonical program to establish targeted innervation that occurs over a rapid time course and precedes auditory experience.

Key words: development; NMDA; AMPA; topography; electron microscopy; 3-D reconstruction

\section{Introduction}

Neural systems that establish mono-innervation via large terminals, such as the neuromuscular junction (NMJ) or climbing fiber input to Purkinje cells, have proven useful to study mechanisms of targeted innervation (Lichtman and Sanes, 2003; Sotelo, 2004). In both of these systems, postsynaptic targets are multiinnervated at or within a few days of birth. Competitive elimination of supernumerary inputs occurs over the first 2-3 weeks of life, likely because of experience-dependent events. The calyx of Held, perhaps the largest nerve terminal in the CNS and a hallmark structure in the auditory brainstem, plays key roles in sound localization and is another example whereby a single input innervates its postsynaptic target (Held, 1893; Warr, 1972; Tolbert and Morest, 1982; Friauf and Ostwald, 1988; Spirou et al., 1990; Smith et al., 1991). However, the process of calyx maturation is not well understood.

The stages of calyx formation have been described in pioneer-

Received Dec. 23, 2005; revised April 11, 2006; accepted April 11, 2006.

This work was supported by National Institutes of Health (NIH) Grant DC005035 and NIH-National Center for Research Resources CoBRE (Centers of Biomedical Research Excellence) Grant RR155174. We thank Brian Pope and Tina Randolph for expert technical assistance and Aric Agmon, Albert Berrebi, Henrique von Gersdorff, and two anonymous reviewers for insightful comments.

Correspondence should be addressed to Dr. George A. Spirou, Sensory Neuroscience Research Center, West Virginia University School of Medicine, P.0. Box 9303 Health Sciences Center, One Medical Center Drive, Morgantown, WV 26506-9303. E-mail: gspirou@hsc.wvu.edu.

DOI:10.1523/JNEUROSCI.5525-05.2006

Copyright $\odot 2006$ Society for Neuroscience $\quad$ 0270-6474/06/265511-13\$15.00/0 ing light-microscopic studies (Morest, 1968b; Kandler and Friauf, 1993; Kil et al., 1995). As described originally in the opossum, a growth cone expands into a protocalyx then further enlarges into a cup-shaped structure, the young calyx, that envelops $\sim 50 \%$ of the postsynaptic cell body (Morest, 1968b; Satzler et al., 2002). These formative stages occur entirely at postnatal ages in rodents and are complete before the onset of hearing between postnatal day 8 (P8) and P10 (Mikaelian and Ruben, 1965; Eggermont, 1985). Dual or triple innervation of postsynaptic targets, the principal neurons in the medial nucleus of the trapezoid body (MNTB), has been revealed in both physiological and anatomical studies around the onset of hearing (Bergsman et al., 2004; Wimmer et al., 2004). The incidence of multi-innervation revealed by these studies was small but considered to be minimal estimates of a more prevalent phenomenon for pruning supernumerary calyces as they mature into their adult form.

As early as $\mathrm{P} 0$, nerve terminals that originate from the cochlear nucleus form synaptic contacts, revealed using electron microscopy, onto MNTB neurons (Kil et al., 1995). We undertook systematic functional and ultrastructural examinations across early postnatal ages to pinpoint when increases in synaptic currents and the number of contacts associated with formation of the protocalyx occur, and to quantify protocalyx growth into a young calyx. In these studies, we performed the first functional assays of nascent synaptic contacts created before and during formation of the young calyx. We revealed, using littermate mouse pups, that 
growth of a protocalyx can begin at P2 and a young calyx can be formed in as few as $48 \mathrm{~h}$. Synapses were functional even before protocalyx formation and exhibited both AMPA and NMDA receptor-mediated neurotransmission. We then determined, using both minimal stimulation electrophysiology protocols and serial electron microscopic sectioning, that the great majority of postsynaptic neurons at the time of young calyx formation are innervated by one large nerve terminal. These data indicate an accelerated time frame to establish targeted innervation that, in contrast to the NMJ and climbing fiber systems, is experience independent.

\section{Materials and Methods}

\section{Recording of synaptic currents from MNTB neurons}

We used mice as our animal model, given developmental parallels with other published studies using rodents and the ability to use transgenic animals in future studies. All protocols were approved by the West Virginia University Institutional Animal Care and Use Committee. Unless indicated otherwise, all reagents were purchased from Sigma (St. Louis, $\mathrm{MO}$ ). The artificial CSF (ACSF) contained the following (in mM): 125 $\mathrm{NaCl}, 2.5 \mathrm{KCl}, 1 \mathrm{MgCl}_{2}, 2 \mathrm{CaCl}_{2}, 25$ glucose, $25 \mathrm{NaHCO}_{3}, 1.25 \mathrm{NaH}_{2} \mathrm{PO}_{4}$, 0.4 ascorbic acid, 3 myo-inositol, and $2 \mathrm{Na}$-pyruvate. Low $\mathrm{Ca}^{2+} \mathrm{ACSF}$ contained $3 \mathrm{mM} \mathrm{MgCl}_{2}$ and $0.1 \mathrm{~mm} \mathrm{CaCl}_{2}$. The ACSF was saturated with $95 \% \mathrm{O}_{2} / 5 \% \mathrm{CO}_{2}$. The internal recording solution contained the following (in mM): $150 \mathrm{CsCl}, 20$ TEA-Cl, 10 HEPES, 5 EGTA, $5 \mathrm{Na}$ phosphocreatine, 4 ATP-Mg, and 3 QX-314 ( $N$-(2,6-dimethylphenylcarbamoylmethyl)-triethylammonium bromide), $\mathrm{pH}$ 7.4. Bicuculline methiodide $(10 \mu \mathrm{M})$ and strychnine $(1 \mu \mathrm{M})$ were added to the ACSF to block inhibitory currents during experiments. CNQX and $(5 S, 10 R)(+)-$ 5-methyl-10,11-dihydro-5H-dibenzo[a,d]cyclohepten-5,10-imine maleate (MK-801) (both at $10 \mu \mathrm{M}$; Tocris Bioscience, Ellisville, MO) were applied to block AMPA and NMDA currents, respectively.

Mouse pups (FVB/NJ strain; The Jackson Laboratory, Bar Harbor, $\mathrm{ME}$ ), aged $\mathrm{P} 0-\mathrm{P} 4$, were decapitated, and brains were dissected and sliced in ice-cold ACSF containing low $\mathrm{Ca}^{2+}$. The brainstem was glued onto a slicing dish mounted on a Series 1000 Vibratome (Vibratome, St. Louis, $\mathrm{MO}$ ). Coronal slices of 200-225 $\mu \mathrm{m}$ containing the MNTB were cut and placed in normal ACSF at $37^{\circ} \mathrm{C}$ for $1 \mathrm{~h}$ and then at room temperature until needed.

All recordings were made at $34-35^{\circ} \mathrm{C}$ in a temperature-controlled RC-26GLP recording chamber (Warner Instruments, Hamden, CT) mounted on a Axioskop II plus microscope (Zeiss, Thornwood, NY). External solutions, pressure driven and controlled by a Valvelink 8 (Automate Scientific, San Francisco, CA), were heated in line (Warner Instruments) and delivered at an approximate rate of $2 \mathrm{ml} / \mathrm{min}$. Digital images of individual MNTB cells were acquired using a C9100-12 EM CCD camera (Hamamatsu, Hamamatsu City, Japan) controlled by Simple PCI image acquisition software (Compix, Cranberry Township, PA) and viewed through a $40 \times$ differential interference contrast (DIC) water-immersion objective (numerical aperture, 0.75 ; Zeiss).

Candidate MNTB cells were selected using the $\mathrm{Ca}^{2+}$-sensitive fluorescent dye fluo-4 AM $(4.5 \mu \mathrm{M})$ or fura- 2 AM (7 $\mu \mathrm{M}$; Molecular Probes, Eugene, OR) as described previously by Billups et al. (2002). Cells were loaded for $5 \mathrm{~min}$ at $35^{\circ} \mathrm{C}$ in the recording chamber. After a $10 \mathrm{~min}$ wash, axons were stimulated at the midline trapezoid body while collecting fluorescent images using a dual FITC/tetramethylrhodamine isothiocyanate filter set (set 5104v2; Chroma Technology, Rockingham, VT). A Lamda DG-4 xenon light source equipped with a shutter (Sutter Instruments, Novato, CA) was used for excitation, and images were captured at a rate of $10-20 \mathrm{~Hz}$. Cells exhibiting transient $\mathrm{Ca}^{2+}$ elevations after stimulation were identified for electrophysiology experiments. Our sample included cells having evoked currents as small as $60 \mathrm{pA}$. Because we did not select cells for the magnitude of $\mathrm{Ca}^{2+}$ signal, this procedure likely did not bias our measurements of current amplitude at any age. For the same reason, we do not think our measurement of the NMDA/AMPA ratio was affected at P3 or P4, because all large terminals likely face both receptor types. It is possible that we selected for higher ratios when currents are small (P1-P2), especially if some terminals did not face either
NMDA receptors or $\mathrm{Ca}^{2+}$ permeable AMPA receptors. However, we did attempt to record extracellular activity in most cases as the pipette approached the cell and observed that $\mathrm{Ca}^{2+}$ imaging, in our hands, was a much more sensitive determinant of connected calyces and MNTB neurons.

Whole-cell voltage-clamp recordings were made using a Multiclamp 700A computer-controlled microelectrode amplifier and a Digidata 1322A digitizer with pClamp 9.0 data acquisition software (Molecular Devices, Union City, CA). Microelectrodes with tip diameters of 2-3 $\mu \mathrm{m}$ were pulled from $1.5-\mathrm{mm}$-diameter borosilicate glass using a P-97 micropipette puller (Sutter Instruments). Tip resistance values were 2-5 $\mathrm{M} \Omega$. Data were acquired at a sampling rate of $20 \mathrm{kHz}$ and filtered at 10 $\mathrm{kHz}$. The average series resistance $\left(R_{\mathrm{s}}\right)$ was $8.4 \mathrm{M} \Omega . R_{\mathrm{s}}$ values were monitored during experiments, and cells with unstable $R_{\mathrm{s}}$ or those with an $R_{\mathrm{s}}$ $>15 \mathrm{M} \Omega$ were not included in our analyses. Series resistance prediction and compensation values were between 70 and $85 \%$ at $7.5-10 \mathrm{kHz}$. Only those cells with stable leak currents $<200 \mathrm{pA}$ at a holding potential of $-70 \mathrm{mV}$ were included in our analyses. Typically, electrophysiology recordings were made from no more than two to three cells per slice over a time span of $1-2 \mathrm{~h}$.

Midline stimulation was delivered through a tungsten matrix electrode $(2: 1$ or $3: 1$ FHC, Bowdoinham, ME) placed at the midline. The centers of the individual parallel microelectrode shafts were spaced 115 $\mu \mathrm{m}$ apart with the tip lengths offset by $235 \mu \mathrm{m}$. With the tips oriented vertically and the electrode mounted at approximately $-26^{\circ}$ on a MP225 micromanipulator (Sutter Instruments), the electrode tips were level with $\sim 260 \mu \mathrm{m}$ of horizontal separation. Stimulation pulses $(0.1 \mathrm{~ms})$ of varying voltage were driven by a S-940/S-910 Stimulus Isolation Unit (Dagan Corporation, Minneapolis, MN), controlled within the pClamp software. For cells at all ages, midline stimulation was delivered at a series of amplitudes between 3 and $30 \mathrm{~V}$. We did not routinely stimulate above $30 \mathrm{~V}$, because stimuli approaching 35-40 V could cause electrolysis and movement of the slice in the bath. For cells from P1-P3 animals, averages of the EPSC amplitude were made using the minimal stimulus value that yielded the maximal postsynaptic current. At P4, the initial stimulus range of 3-30 V provided an estimate for the number of convergent inputs. To create the detailed minimal stimulation protocols, four sets of randomized numbers between 1 and 10 were created and concatenated. Separate protocols using the same list of stimuli were scaled by $2-4 \times$, thus producing protocols with maximal stimulus values of 20,30, and 40 $\mathrm{V}$ having four stimuli at each stimulus voltage. A particular scaled protocol was selected based on the initial estimate of threshold exhibited by an individual cell. In this manner, we were able to provide finer estimates of threshold for low threshold inputs to increase our certainty that a second input with a similar threshold to the first was not overlooked. For some preparations, we were able to use stimuli up to $40 \mathrm{~V}$ for higher threshold inputs if no significant movement of the slice occurred in the bath.

We also used a rundown protocol, based on procedures used by Bergsman et al. (2004), that takes advantage of rapid adaptation in evoked currents. The goal of the rundown protocol was to minimize the EPSC recorded at threshold and increase the stimulus to look for secondary inputs that were activated by higher-amplitude stimuli. An amplitude at or above the stimulus threshold, determined by first running the minimal stimulation protocol, was chosen for the first stimulus. The second stimulus amplitude was at least 1.5-fold larger than the first.

NMDA receptor-mediated currents for $\mathrm{P} 2-\mathrm{P} 4$ were estimated by subtracting scaled AMPA currents (recorded at $-75 \mathrm{mV}$ ) from currents recorded at holding potentials between -50 and $+75 \mathrm{mV}$ using Matlab 7.0.1 (Mathworks, Natick, MA). These estimations were nearly identical to NMDA and AMPA receptor-mediated current amplitudes measured from cells bathed in the AMPA and NMDA receptor antagonists CNQX and MK-801 (both $10 \mu \mathrm{M}$ ) (see Fig. 1A,B). At P1, AMPA and NMDA receptor-mediated currents at $+75 \mathrm{mV}$ were reliably estimated by measuring the respective inflection points or peaks in the current traces, because the peak for the NMDA current was quite delayed relative to the peak for the AMPA current.

Average EPSC amplitudes for individual cells were calculated from all EPSCs elicited during minimal stimulation protocols. For profiles of 
responses that showed apparent gradations that might indicate multiple inputs, we compared statistically the groups of stimulus voltages across these gradations and also compared response values pairwise across all stimulus voltages. For cells receiving two large inputs, the difference between the lower-threshold EPSC amplitude and the combined EPSC amplitudes was used to estimate the amplitude of the higher threshold input. Response latencies were measured from the onset of the stimulus artifact to the onset of the EPSC. Data analysis was performed using Clampfit 9.2 (Molecular Devices) and Origin 7.5 (OriginLab, Northampton, MA). Average values are presented \pm SEM, and statistical comparisons were made using the Student's $t$ test with Statmost 3.6 software (Dataxiom, Los Angeles, CA).

\section{Serial section electron microscopy}

Mouse pups, from the same strain and of the same ages as were used in electrophysiology experiments, were anesthetized by hypothermia and either they were perfused transcardially with a calcium-free Ringer's solution followed by a mixture of $2 \%$ paraformaldehyde and $2.5 \%$ glutaraldehyde in $0.12 \mathrm{~m}$ phosphate buffer, $\mathrm{pH} 7.3$, or their brains were dissected, after decapitation, while their skulls were immersed in warm fixative. Both fixation methods yielded well preserved tissue samples. Each brainstem was cut into $200-\mu \mathrm{m}$-thick sections in the coronal plane, postfixed with $1 \%$ osmium tetroxide, stained with $2 \%$ uranyl acetate, dehydrated, and flat-embedded in Epon. Tissue containing the MNTB was re-embedded and trimmed for cutting semithin $(0.5-1 \mu \mathrm{m})$ and ultrathin $(70 \mathrm{~nm})$ sections. Postembedding glycine immunolabeling and toluidine blue staining were performed on adjacent pairs of semithin sections to identify the boundaries of the MNTB. One animal at each age was selected for serial section and ultrastructural analysis of the density of synapses and puncta adherentia on MNTB cell somata. Sequences of up to 70 serial ultrathin sections were collected and stained with $0.5 \%$ uranyl acetate and 3\% lead citrate using an automated grid stainer (Leica, Wetzlar, Germany). A subset of 35 sequential sections, $70 \mathrm{~nm}$ thick as estimated by the color of tissue sections and taken from the mid rostrocaudal region of the nucleus of each animal, was examined using a JEOL (Tokyo, Japan) 1010 electron microscope. At least one additional animal at each age was surveyed to determine that ultrastructural features were consistent within ages. Litters were born during the night, and pups were killed near midday at each age.

Density of synaptic and adherens contacts on MNTB somata. A photomontage of the entire MNTB from each animal aged P0-P4 was assembled at low magnification $(800 \times)$, and the MNTB was divided into four to five regions along its tonotopic, medial (high-frequency) to lateral (low-frequency) axis (Sommer et al., 1993). Data from all regions were qualitatively similar and were combined for each age. Within each region, a field of view maintained through all serial sections was chosen by identifying a cell body near the center of the region. One image per region was taken at a magnification of $2000 \times$ on each section in the series, through a total tissue depth of $\sim 2.5 \mu \mathrm{m}$. Synapses and puncta adherentia were identified within each region by inspecting photomicrographs at a final magnification of $32,000 \times$ and were considered to represent structural evidence for functional contacts between cells. Synapses were classified by the presence of a postsynaptic density apposed to a presynaptic active zone that contained a vesicle cluster. Puncta adherentia were classified by the presence of symmetric membrane-associated densities at the apposition of two cells in the absence of synaptic vesicles. We also inspected nerve terminals for the presence of mitochondria-associated adherens complexes (MACs) (Rowland et al., 2000). See Results for a description of this organelle complex.

Selected structures, typically specialized contacts and internal features of the protocalyx, were photographed at $10,000 \times$ and viewed at a final magnification of up to $80,000 \times$. Higher-magnification images were collected to verify conclusions drawn at lower magnification and to evaluate features such as synaptic vesicle shape that could not be assessed at lower magnification. Photographic negatives were digitized using a flatbed scanner (Epson 1680), and somatic perimeters of MNTB neurons, together with the length of postsynaptic densities and puncta adherentia along the somatic surface, were measured using the segmented line drawing tool in ImageJ (http://rsb.info.nih.gov/ij/). These values, summed over all 35 sections, were used to calculate the fraction of MNTB somatic surface contacted by synapses and puncta adherentia.

Evaluating convergence of calyceal inputs at P4. A separate series of 306 serial sections was collected from the same P4 mouse pup used in the analysis of somatic functional contacts described above, to count the number of calyceal contacts onto individual MNTB cells. Montages of the medial half of the MNTB were prepared at intervals of $280 \mathrm{~nm}$ (every fourth section), because the medial edges of the MNTB are more easily discerned than the lateral half, which borders other cell groups. Cell body perimeters, calyces and their associated axons, and smaller inputs not linked to calyces were identified and traced through the serial montages. Selected intervening sections were photographed to eliminate ambiguities in linking structures through the tissue depth. The total surface area of the soma and the surface area contacted by synaptic inputs were quantified using ImageJ, as described above. Small inputs extended over relatively few sections, so their size was most reliably quantified from cells reconstructed in three dimensions (see below), because each section was precisely aligned for rendering these images.

A subset of neighboring MNTB cells with their associated inputs from this series of sections was reconstructed in three dimensions. For this purpose, photographic negatives were scanned at a resolution of 1200 dpi. Images were imported into software for alignment and tracing of the calyx-forming axon with its nerve terminal and the MNTB cell body, proximal dendrite, and nucleus (Reconstruct software by John Fiala, www.synapses.bu.edu/tools). Resultant drawing interchange format (.dxf) files were imported into Carrara 4 Pro (Eovia, Mountain View, CA) for rendering.

Postembedding glycine immunocytochemistry for light microscopy Semithin sections $(0.5-1 \mu \mathrm{m}$ thick) that bracketed series of ultrathin sections were processed on glass slides for postembedding glycine immunocytochemistry [see Spirou and Berrebi (1997) for detailed procedures]. Epon was etched from the tissue by using 10-20\% sodium hydroxide dissolved in ethanol (Lane and Europa, 1965). Osmium was removed from the sections with sodium periodate (1\%). Sections were rehydrated, immersed for $1 \mathrm{~h}$ in 5\% normal donkey serum, and incubated overnight at room temperature with a polyclonal rabbit antiserum against bovine serum albumin-glutaraldehyde conjugated with glycine (1:1200 dilution; Chemicon, Temecula, CA). After rinsing, the sections were incubated in a biotinylated secondary antibody and processed by using the avidin-biotin complex method (Vector Laboratories, Burlingame, CA) with 3,3' diaminobenzidine as the chromogen.

\section{Results}

\section{Identification of the MNTB in neonatal animals}

As has been demonstrated in many species (Campistron et al., 1986; Peyret et al., 1987; Aoki et al., 1988), immunolabeling with antibodies against glycine reveals readily discernible MNTB neurons within the superior olivary complex. We used the same criterion to verify that the MNTB formed a homogeneous cell group at these young ages. An example of glycine-immunoreactive cells from a P1 animal is shown in supplemental Figure 1 (available at www.jneurosci.org as supplemental material), which is representative of the appearance of the MNTB between P0 and P4. As in adult animals, the MNTB appears to be approximately oval in structure, several cells thick in the dorsoventral dimension, and $\sim 700 \mu \mathrm{m}$ wide (within the dashed line in supplemental Fig. 1, available at www.jneurosci.org as supplemental material). To identify cells for electron-microscopic analysis, we used toluidine blue staining (data not shown) to reveal neurons clustered in the same location as the glycine-immunolabeled cells. For brain slice experiments, we used DIC optics to identify a cluster of neurons in neonatal animals consistent in position and arrangement with the MNTB identified histologically from our anatomical studies. All recordings were made from neurons in this cell cluster. 
Rapid growth of postsynaptic currents occurs at early postnatal ages

Whole-cell voltage-clamp recordings were made from brain slices at $\mathrm{P} 1-\mathrm{P} 4$ to determine whether synapses are functional and drivable via electrical stimulation of the axon. MNTB neurons exhibiting postsynaptic $\mathrm{Ca}^{2+}$ responses to midline stimulation, as revealed through the use of $\mathrm{Ca}^{2+}$. senstitive fluorescent dyes (see Materials and Methods), were selected for study. Both AMPA and NMDA receptormediated currents contributed to the postsynaptic response to electrical stimulation (Fig. 1 $A, B$ ). Both currents reversed at the same holding potential, although the NMDA component was larger at positive membrane potentials. The amplitudes of both components were compared at a holding potential of $+75 \mathrm{mV}$, in which the NMDA component could be easily measured. From P1 to P4, the AMPA receptormediated currents increased 30 -fold from $0.114 \pm 0.039$ to $3.568 \pm 0.402 \mathrm{nA}$, and the NMDA receptor-mediated currents increased 17-fold from $0.251 \pm 0.097$ to $4.294 \pm 0.471 \mathrm{nA}$. The largest increases for both components occurred between P3 and $\mathrm{P} 4$ (Fig. 1C). Interestingly, the ratio of AMPA to NMDA receptor-mediated currents increased from $\mathrm{P} 1$ to $\mathrm{P} 4: \mathrm{P} 1,0.45 ; \mathrm{P} 2$, $0.68 ; \mathrm{P} 3,0.64 ; \mathrm{P} 4,0.83$. In agreement with previous work on postnatal mice focused on ages older than P4 up to P18 (Futai et al., 2001; Joshi and Wang, 2002), we show that both current types grow rapidly during early calyx development, with the relative contribution of AMPA receptors increasing over time (Fig. 1C).

We then focused on changes in the amplitude of AMPA receptor-mediated currents recorded from neurons at a holding potential of $-70 \mathrm{mV}$, which is closer to the resting membrane potential. At $\mathrm{P} 1$, the average stimulus-evoked AMPA receptormediated EPSCs were $-0.14 \pm 0.04 \mathrm{nA}$.

This value increased to $-0.44 \pm 0.07 \mathrm{nA}$ at $\mathrm{P} 2$ and further increased to $-6.71 \pm 0.65 \mathrm{nA}$ at $\mathrm{P} 4$ (Fig. $1 D, E$ ). Smaller stimulus-evoked glutamatergic EPSCs were often observed in addition to the larger calyx-mediated EPSCs. At P4, these smaller-amplitude noncalyceal events were distinguished from the larger calyx-mediated EPSCs by their size and longer latencies (see below).

\section{Structural development mirrors physiological observations}

Very few axosomatic contacts occur at $P 0$ and $P 1$

Our observations on the ultrastructure of the MNTB in neonatal animals are based on investigation of multiple serial sections through multiple cells at each time point and therefore do not rely on impressions gained from single electron micrographs. To quantify calyx growth, we measured the fraction of somatic surface that comprises functional contacts (postsynaptic densities, puncta adherentia) with presynaptic terminals across the age

C
D

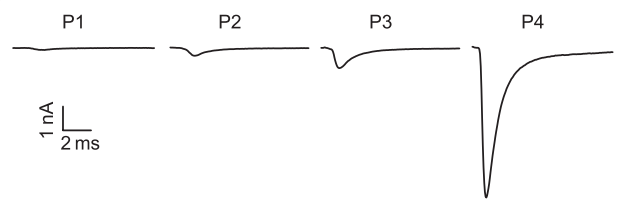

$E$

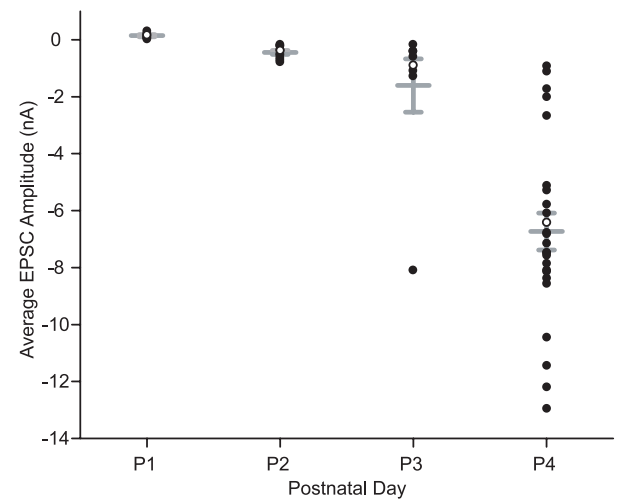

Figure 1. Synaptic currents have both AMPA and NMDA receptor-mediated components that increase with age. $\boldsymbol{A}$, Amplitudes

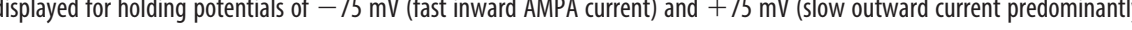
CNQX (10 $\mu \mathrm{m} ;$ ) or MK-801 (10 $\mu \mathrm{m} ; \bigcirc)$, respectively. Current traces were recorded at $\pm 75 \mathrm{mV}$ holding potentials, as in $\boldsymbol{A}$. $\boldsymbol{A}$ recordings. $\boldsymbol{E}$, EPSC amplitudes, averaged for individual cells at a $-70 \mathrm{mV}$ holding potential, are plotted for P1-P4. Gray horizontal bars denote averages \pm SEM for each age. Note the different holding potential for data displayed in $\boldsymbol{C}$ and $\boldsymbol{E}$.

range $\mathrm{P} 0-\mathrm{P} 4$. Here, we have grouped our observations of $\mathrm{P} 0$ and $\mathrm{P} 1$ together, because MNTB ultrastructure is very similar for both ages.

Few synaptic connections are made with the somatic surface during the first two postnatal days (Fig. 2; supplemental Fig. 2, available at www.jneurosci.org as supplemental material). This low incidence of somatic contacts occurs despite the intermingling of axons, MNTB cell bodies, and dendrites. Synaptic contacts are more typically found in the neuropil but are not in high density there either. Some postsynaptic structures in the neuropil were traced, through serial sections, and found to arise from MNTB cell bodies, indicating that many of these contacts are made onto MNTB neurons [cell 1 in supplemental Fig. 2 (available at www.jneurosci.org as supplemental material) is depicted where its dendrite is linked to the cell body]. Dendrites that could not be linked to a cell body within the range of serial sections are colored red; these likely belong to MNTB cells or possibly extend into the MNTB from nearby cell groups. 

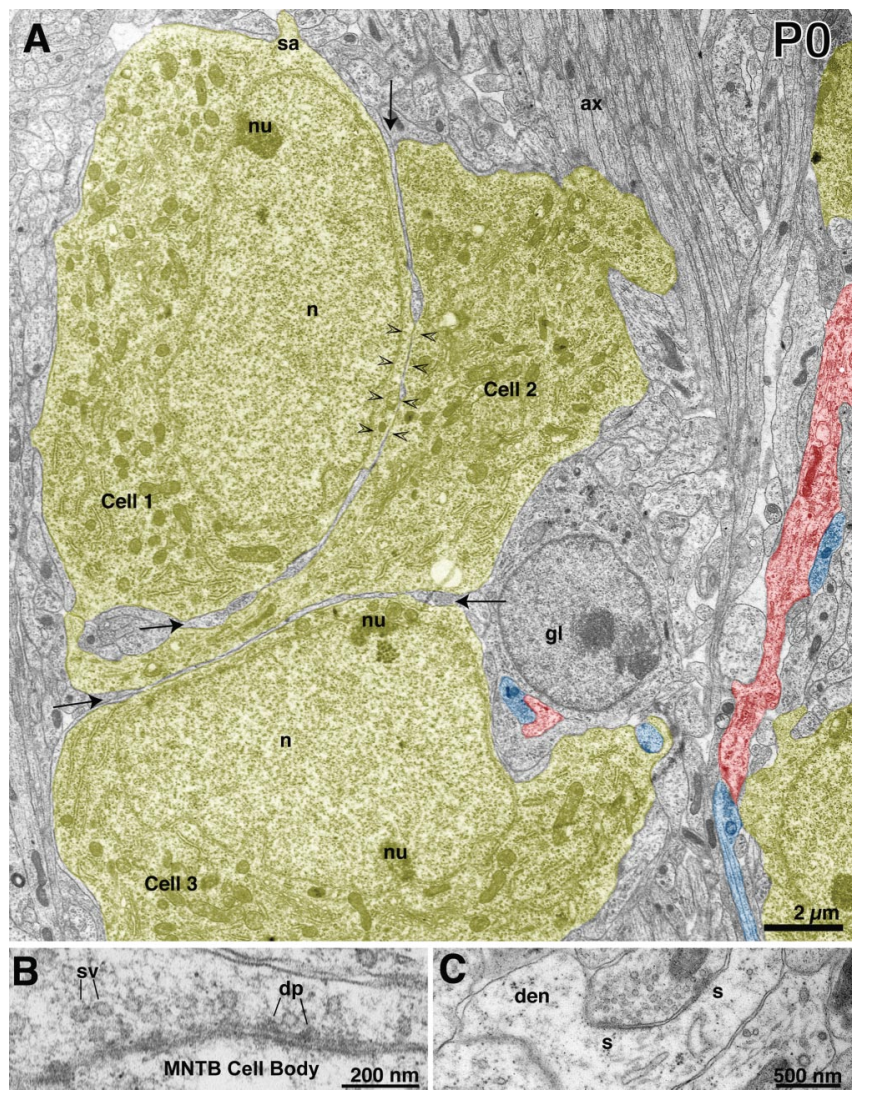

Figure 2. MNTB neurons at PO form clusters and receive few synaptic inputs. $\boldsymbol{A}$, Cell bodies (gold) are separated by thin cellular processes (arrows) over long distances, although they also do come into contact with dendrites and somata of adjacent cells (arrowheads at contact between cells 1 and 2). Nuclei (n) are eccentrically placed and contain multiple nucleoli (nu) or regions of condensed heterochromatin, often apposed to the nuclear membrane. Active zones are found in presynaptic cellular processes (blue) that are apposed to postsynaptic densities in cell bodies or dendrites. Postsynaptic dendrites that were not linked to an MNTB cell body within the series of sections are highlighted in red. A glial cell $(\mathrm{gl})$ is in contact with cells 2 and 3. Cell 2 is in apposition to numerous axons (ax) of a trapezoid body fiber bundle. sa, Somatic appendage, small hair-like protrusion of the cell body. $\boldsymbol{B}$, Standard features of synaptic machinery, including presynaptic dense projections (dp) and synaptic vesicles (sv), characterize functional contacts. A synapse was made onto an MNTB cell body. C, Synapses (s) onto dendrite (den). All terminals contain round synaptic vesicles.

At $\mathrm{P} 0$ and $\mathrm{P} 1$, nerve terminals in the MNTB are small and are located at the end of a typically thin process. These processes (Fig. 2 , blue) could be thin axons or growth cone processes and may originate from the cochlear nucleus (Kil et al., 1995); they could not be traced to their origin within the set of serial sections. A closer examination of functional contacts reveals both synapses (Fig. $2 B, C$ ) and puncta adherentia (data not shown for this age). Synaptic contacts contain the typical elements of synaptic machinery. In all terminals investigated at high magnification at each age $(\mathrm{P} 0-\mathrm{P} 4)$, clusters of round vesicles are located near the active zones. Although the prevalence of specialized contacts onto the cell body is low at P0 and P1, synapses are in greater abundance than puncta adherentia (Table 1).

Large somatic terminals are first detected at P2

Dramatic changes in the nature of somatic innervation occur between P1 and P2 (Fig. 3). At P2, large presynaptic endings, termed early protocalyces (Morest, 1968b), are detectable on the somatic surface. The axon leading into the protocalyx (data not shown) is thicker than the axonal process leading into small nerve terminals at $\mathrm{P} 0$ and $\mathrm{P} 1$. These large endings appear to extend over less than one-half of the cell body perimeter when captured tangentially through our series of ultrathin sections (Fig. $3 A$ ). The amount of somatic surface covered by postsynaptic densities and puncta adherentia increased fourfold to fivefold relative to P1 (Table 1).

Inspection of the large terminal onto cell 4 in Figure 3 reveals two long stretches of synaptic and punctum adherens contacts, located to either side of the region enlarged in Figure $3 B$. In the region shown in Figure $3 B$, the terminal is separated from the MNTB cell body by thin, membrane-enclosed processes or other thicker cellular elements. The active zones within these terminals could be large (Fig. 3D), as reported for P5 calyces in rats (Taschenberger et al., 2002), and are apposed to the smooth portion of the somatic surface or somatic appendages (Fig. $3 E$ ). Large postsynaptic densities have been described recently in other developing systems (Cathala et al., 2005) and may support appropriate levels of cellular communication during calyx development. Numerous dense-cored vesicles are found near active zones or away from the cell membrane within the core of the nerve terminal (Fig. 3B, $D-F$ ).

In other sections from this series, the tip of this early protocalyx extends away from the MNTB cell and resembles the solitary process defined using the Golgi stain (Morest, 1968b). Solitary processes are typical features of protocalyces, but their internal structure has not been investigated previously. Electron microscopy reveals that the solitary process is filled with vesicles of various sizes including an occasional dense-cored vesicle and a multivesicular body (not found in this tissue section). Despite the presence of a high density of vesicles, the solitary process does not form synaptic contacts with apposed cellular processes (Fig. $3 F$ ).

Large somatic terminals may contact every cell at P3

The trend toward increased somatic innervation at P2 is continued at P3 (Fig. 4A,B). Nearly all cells are contacted at numerous sites along their somatic surfaces. When following cells through serial sections, we found that nerve terminals often extend across nearly one-half of the somatic perimeter and, similar to adult calyces, can appear to be embedded into the membrane surface (Fig. $4 A, B$, asterisk). These terminals appear to be transitional in size between early protocalyces encountered at P2 and typical images of young calyces from other rodents and bats at $\sim 1$ week of age (Kuwabara et al., 1991; Kandler and Friauf, 1993; Satzler et

Table 1. Functional contacts with somatic membrane (percentage of surface)

\begin{tabular}{llllll}
\hline & P0 & P1 & P2 & P3 & P4 \\
\hline Postsynaptic density & $0.31 \pm 0.3 \%$ & $0.28 \pm 0.3 \%$ (0.9-fold) & $1.28 \pm 0.8 \%$ (4.1-fold) & $3.50 \pm 2.0 \%$ (11.3-fold) & $4.83 \pm 0.4 \%$ (15.6-fold) \\
Punctum adherens $^{\text {Number of MNTB regions measured }}{ }^{a}$ & $0.04 \pm 0.02 \%$ & $0.12 \pm 0.1 \%$ (3-fold) & $0.60 \pm 0.3 \%$ (15-fold) & $0.96 \pm 0.4 \%$ (24-fold) & $2.93 \pm 0.4 \%$ (73-fold) \\
\hline
\end{tabular}

Data are mean \pm SD.

${ }^{a}$ Values in parentheses reflect the number of cells with complete perimeters measured across serial sections at each age. Somatic membranes of additional cells were partly included in the measurement field and are included in this analysis. The MNTB was divided into four (or five at P3) equal regions oriented from medial to lateral. Measurements for each complete or partial cell were placed into the appropriate region and combined as a single measurement for that region. Therefore, means and SDs are based on the number of regions analyzed at each age. 
al., 2002). Synaptic contacts with the MNTB cell resemble those found at P2, in that postsynaptic densities are often large and presynaptic terminals contain densecored vesicles (Fig. 4D). The increased prevalence of specialized contacts is reflected primarily by a threefold increase, relative to $\mathrm{P} 2$, in the percentage of somatic surface devoted to synaptic junctions ( $\mathrm{Ta}$ ble 1). MACs are first detected at this age (Fig. 4C), although they are much less prevalent than in the adult calyx. The salient features of the MAC, as described for calyces and large terminals of auditory nerve fibers in cats (Cant and Morest, 1979; Tolbert and Morest, 1982; Rowland et al., 2000), are a mitochondrion positioned near the presynaptic membrane, a punctum adherens, vesicular or tubular membrane interposed between them, and filaments extending from the punctum adherens to a plaque adjacent to the mitochondrion. We have proposed homeostatic roles for this organelle complex, such as $\mathrm{Ca}^{2+}$ buffering to support high-rate synaptic transmission (Rowland et al., 2000), which may become important only after the protocalyx has reached a particular size threshold.

\section{Young calyces form at $\mathrm{P} 4$}

The most striking change observed at P4 is the expansion of the large terminals around the MNTB cell soma. Nearly all MNTB cell bodies are contacted by large endings, which can envelop much of the cell perimeter when viewed in individual ultrathin sections (Fig. 5A). In this regard, the largest endings encountered at this age appear to form a cup over much of the somatic surface, resembling a developmental stage termed the young calyx (Morest, $1968 \mathrm{~b})$.

Long stretches of the calyx adhere to the MNTB cell via sequences of synaptic and adhering junctions (Fig. 5B). Young calyces contain many clear synaptic vesicles, that are grouped into clusters near the active zones. The active zones can be large (data not shown), as described for P3 endings. The percentage of somatic surface devoted to functional contacts nearly doubles from $\mathrm{P} 3$ to $\mathrm{P} 4$, reflecting increases in both postsynaptic densities and puncta adherentia (Table 1). As at $\mathrm{P} 2$ and $\mathrm{P} 3$, regions of specialized contact can be separated by stretches of membrane in which cellular processes (up to $0.5 \mu \mathrm{m}$ in thickness) interpose between the calyx and the MNTB cell. Similar to earlier ages, dense-cored vesicles are prevalent and are located both near the presynaptic membrane and dispersed in the middle of the nerve terminal

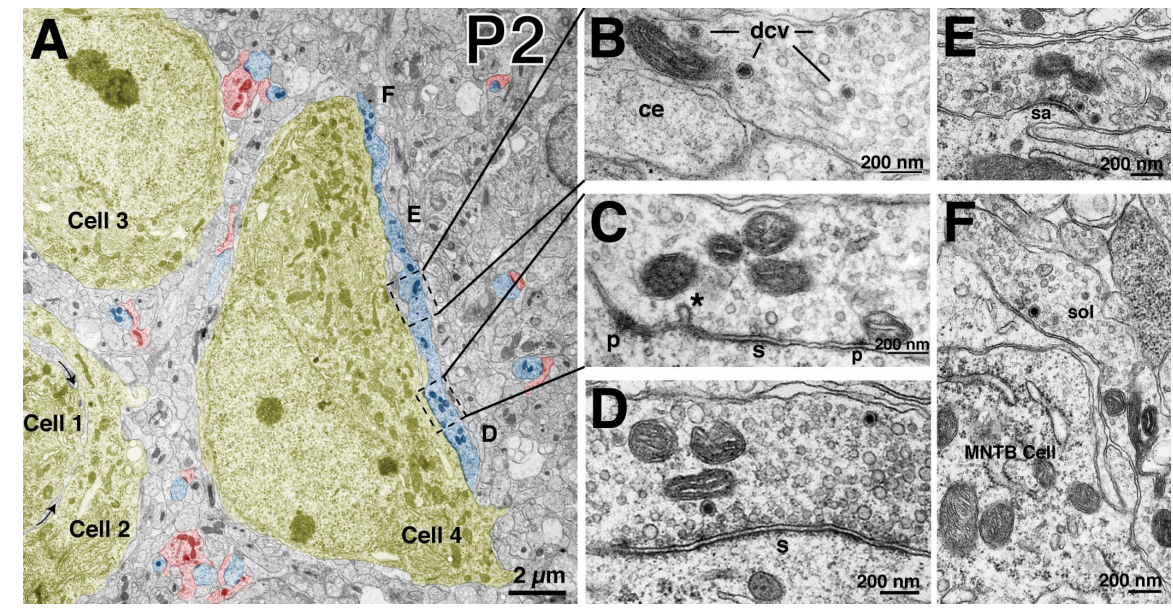

Figure 3. Protocalyces form at P2. A, The protocalyx appears as a thickened process, in apposition to the soma of cell 4. The protocalyx and small presynaptic terminals in the neuropil are highlighted in blue and were not linked within the series of sections. Both synaptic and punctum adherens contacts form between the protocalyx and the cell body, onto its smooth surface (in $\boldsymbol{C}$ and $\boldsymbol{D}$ ) and onto somatic appendages (sa; in $\boldsymbol{E}$ ). As at P0 and P1, MNTB cell bodies are separated by thin cellular processes (curved arrows between cells 1 and 2) or in direct contact (data not shown). Regions enclosed by dashed boxes are enlarged in $\boldsymbol{B}$ and $\boldsymbol{C}$. $\boldsymbol{B}-\boldsymbol{E}$, Synaptic ( $s$ ) and punctum adherens ( $p$ ) contacts between protocalyces and MNTB cell bodies. $\boldsymbol{B}$, Stretches of synaptic and punctum adherens contacts are separated by regions where cellular elements (ce) or thin processes insinuate between the nerve terminal and the cell body. C, A large coated, possibly endocytosing vesicle (asterisk) is interposed between a synapse and punctum adherens. $\boldsymbol{D}-\boldsymbol{F}$, Electron micrographs taken from same protocalyx as in $\boldsymbol{A}$, but different tissue sections. Letters indicate regions of the protocalyx that are enlarged in the corresponding panel. $\boldsymbol{D}$, Postsynaptic densities can be long and apposed to regions of densely packed vesicle clusters. Some vesicles are in contact with the presynaptic membrane. $\boldsymbol{E}$, Synapses can form onto somatic appendages (sa). $\boldsymbol{F}$, The extension of the protocalyx beyond the MNTB cell body is termed a solitary process (sol). This process does not form synaptic endings but is filled with large and small vesicles. Dense-cored vesicles (dcv; in $\boldsymbol{B}$, not labeled but present in $\boldsymbol{D}-\boldsymbol{F}$ ) are found both near and away from the presynaptic membrane and in the solitary process.
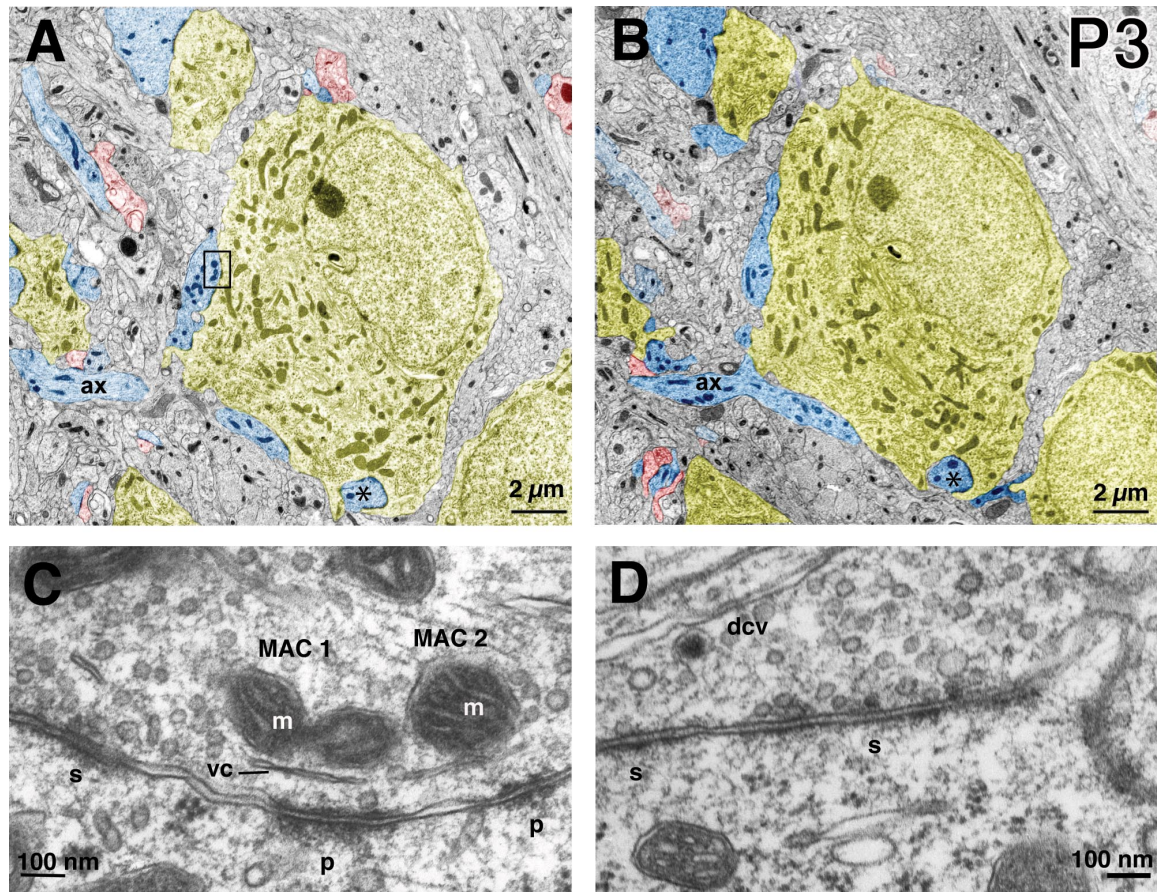

Figure 4. Late-stage protocalyx growing into young calyx at P3. $A, B$, Two sections from a series showing the innervation of a significant portion of the somatic surface by a single large-diameter axon (ax). This axon and other axons, along with nerve terminals, are colored blue. Synaptic contacts from axons that do not link in our series of sections to the large axon innervating the cell body are also made onto dendrites in the neuropil (red) and a different cell body at the top left of each panel (all cell bodies colored gold). C, MACs (two are enlarged from the solid box in $A$ ) are first detected at P3. MAC components are a punctum adherens $(\mathrm{p})$, vesicular chain (vc), and a mitochondrion $(\mathrm{m})$ positioned nearby the presynaptic membrane. D, Synapses (s) from another late-stage protocalyx. The synapse on the right has a long postsynaptic density, and a terminal contains clear round vesicles, some of which are in contact with the presynaptic membrane and a dense-cored vesicle (dcv). 

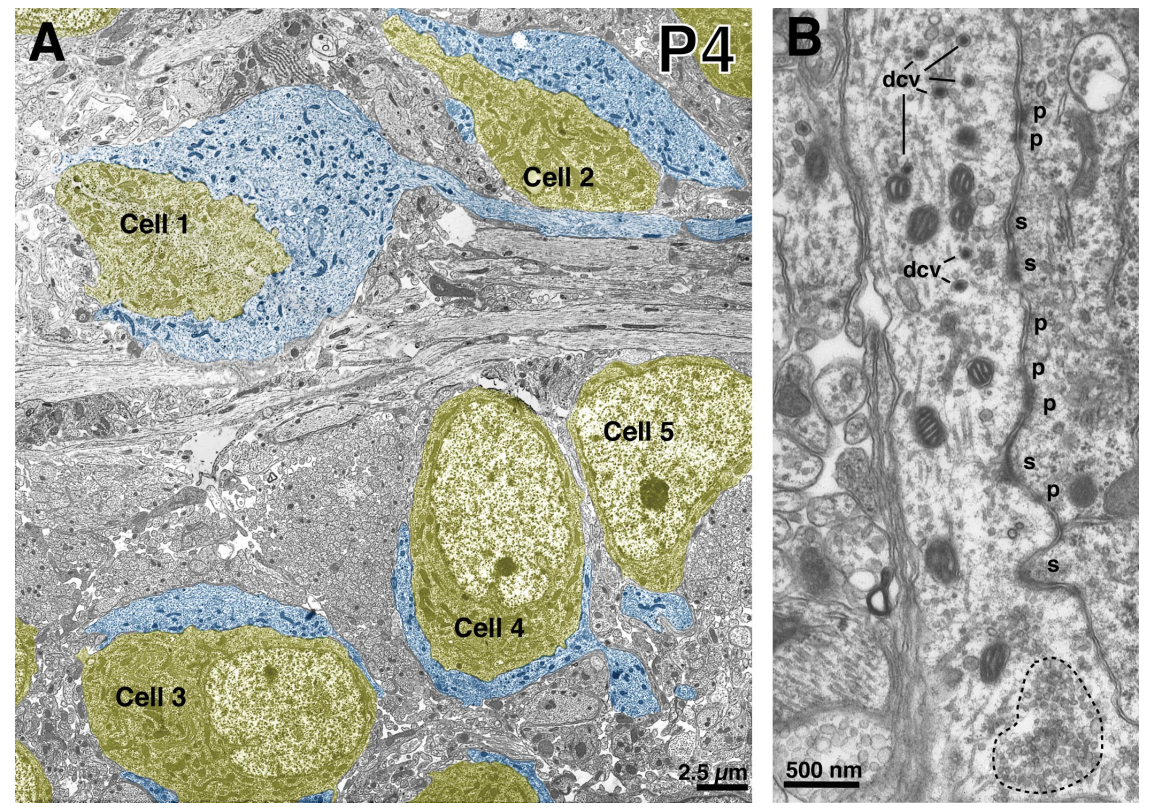

Figure 5. Young calyces are first detected at P4. A, Even in single transverse sections, most neurons are contacted by large endings, some of which appear to envelop the cell body. A large ending onto cell 1 can be traced to its axon in the trapezoid body. The largest cells are numbered to indicate that they are revealed to be distinct neurons through serial sections. B, Calyx and somatic membrane are zippered together by synapses ( $s$ ) and puncta adherentia ( $p$ ). Clusters of clear vesicles become apparent at this age (enclosed by dashed line), and dense-cored vesicles (dcv) are commonly seen.

(Fig. 5B). In cultured hippocampal neurons, dense-cored vesicles contain the active zone-associated proteins, piccolo and bassoon, and represent prefabricated active zones for insertion into the presynaptic membrane (Zhai et al., 2001; Shapira et al., 2003). The dense-cored vesicles we observe are of similar size $(80 \mathrm{~nm}$ diameter) and could serve the same role in the growing calyx.

\section{Characteristics of the MNTB cell body}

Between P0 and P2, cell bodies of the MNTB are often situated adjacent to one another. Long stretches of the membranes can be separated by thin cellular processes or directly apposed (Figs. $2 \mathrm{~A}$, $3 A)$. At P3 and P4, the spacing between cell bodies increases, probably to make room for enlarging nerve terminals, yet dendrites and somata of neighboring cells do come into direct apposition. Therefore, ultrastructural investigation is necessary to reveal functional contacts in this tightly packed arrangement of neurons and their synaptic inputs. Despite these direct contacts between cells, we did not detect tight junctions or other adhering structures at any of these ages. Somata at P4 appear rounder and begin to establish their adult-like ellipsoid shape, an impression that is confirmed by three-dimensional reconstructions (see below). This morphological alteration of MNTB somata precedes similar changes in spherical bushy cells of the cochlear nucleus, which are themselves contacted by large nerve terminals of auditory nerve fibers (Limb and Ryugo, 2000). Unlike the adult, the cell nucleus in the neonatal animal is eccentrically located very close to the somatic membrane, with nuclear and cytoplasmic membranes as close as $200 \mathrm{~nm}$ (Figs. $2 A, 3 A, B, 4 A, B, 5 A$; supplemental Fig. 2, available at www.jneurosci.org as supplemental material), thereby defining the nuclear pole of the cell. Before protocalyx formation ( $\mathrm{P} 0-\mathrm{P} 1)$, nuclei appear irregular in shape, matching the contour of the cell membrane.

\section{Physiological recordings indicate mono-innervation}

Because calyceal inputs at $\mathrm{P} 4$ have reached or were reaching the developmental stage of the young calyx, we performed separate functional and structural analyses to determine whether single MNTB neurons are innervated by more than one large nerve terminal at this age. In adult animals, using techniques to bulk label axons and their calyceal terminals, there have not been documented occurrences of more than one calyx contacting single MNTB neurons (Tolbert et al., 1982; Berrebi and Spirou, 1998). Thus, multiple innervation would be evidence for competition among inputs. Analysis of $\mathrm{P} 4$ animals permits a more direct comparison to the motor neuron and climbing fiber afferents, which achieve a large size by this same age as they compete for postsynaptic targets. Furthermore, calyx-induced synaptic currents have become large at $\mathrm{P} 4$, so evidence of multiple innervation is more easily assessed physiologically than at younger ages.

We used two electrical stimulation protocols that allowed us to detect multiple large inputs and estimate their magnitudes. First, a minimal stimulation protocol was applied to determine the threshold of activation for each input. This approach was initially applied to large nerve terminals of the auditory brainstem to estimate the number of auditory nerve inputs converging onto single neurons of the chick nucleus magnocellularis, homolog of the mammalian anteroventral cochlear nucleus (Jackson and Parks, 1982). For this protocol, we adjusted the stimulus range to more precisely map low thresholds, so as not to miss additional inputs, or to extend the stimulus range for high threshold inputs (see Materials and Methods). Second, after establishing activation thresholds, we applied a rundown protocol adapted from Bergsman et al. (2004), whereby a train of stimuli were applied to fatigue the lower threshold input before activating any higher threshold inputs with an increase in stimulus intensity. Of the 29 cells that we examined in this study, 17 were studied using both protocols. Of these 17, two exhibited the physiological signatures of two large inputs, and these inputs were evident using both protocols. Activation of one or both inputs produced EPSCs with identical reversal potentials that were composed of AMPA and NMDA components. Figure 6 shows recordings from two cells, one of which was singly $(A, B)$ and the other doubly $(C, D)$ innervated. The singly innervated cell exhibited a fast large current in response to midline stimulation, which had a distinct threshold at $6 \mathrm{~V}$. The rundown protocol revealed rapid synaptic depression within $\sim 20$ stimuli, and the jump to a larger stimulus amplitude (by a factor of $3 \times$ ) did not recruit additional inputs. In contrast, the responses from another cell revealed two distinct steps in the magnitude of the response with increases in stimulus amplitude using the minimal stimulation protocol (Fig. 6C). The second input was also evident using the rundown protocol and also adapted very quickly (Fig. 6D). Another 12 cells were studied using only the minimal stimulation protocol. Overall, 4 of the 29 cells that were studied exhibited the physiological signatures of two large inputs (Fig. 6E). Although the average EPSC amplitude of each individual input within the pair of large dual inputs could be $<1 \mathrm{nA}$ (range, -0.81 to -2.15 $\mathrm{nA}$ ), each input was capable of producing an individual EPSC $>1$ $\mathrm{nA}$ (Fig. 6C) and the average amplitude of each of the paired 
A

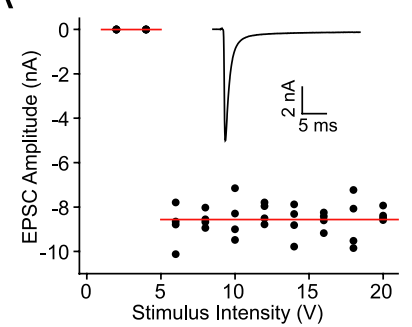

C

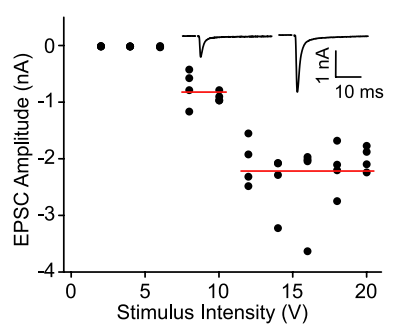

B

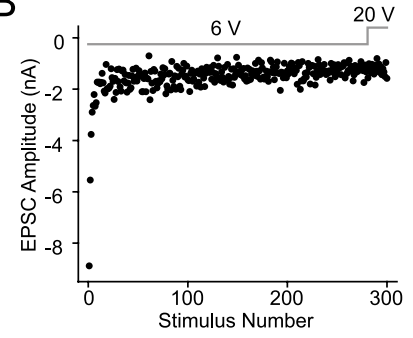

D

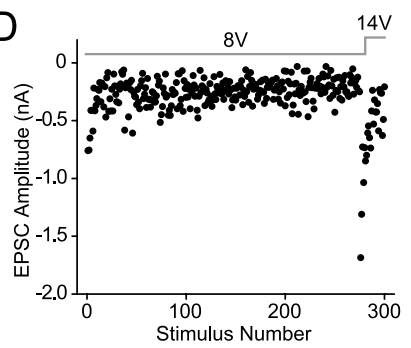

E

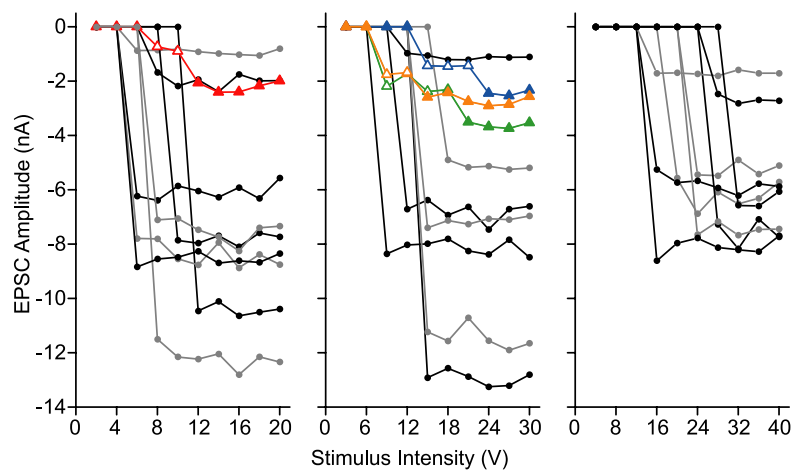

Figure 6. Shock-evoked synaptic currents at P4 are consistent with innervation of most MNTB cells by a single large synaptic input. $\boldsymbol{A}$, Minimal stimulation protocol applied to a representative MNTB cell at P4 showing an all-or-none response, indicative of a single calyceal input. Four random runs of this minimal stimulation protocol were delivered via midline stimulation at $0.2 \mathrm{~Hz}$. The red horizontal line is the average amplitude of all EPSCs. Inset, Average waveform of all EPSC in this experiment. $\boldsymbol{B}, \mathrm{A} 2 \mathrm{OHz}$ stimulus train delivered to the same cell in $\boldsymbol{A}$ to adapt the evoked current. No increase in the EPSC amplitude is observed when increasing the stimulus intensity from 6 to $20 \mathrm{~V}$. Stimulus intensity is indicated by the gray horizontal bar. C, Minimal stimulation protocol applied to an MNTB cell exhibiting multiple innervation. Red horizontal lines show averages of EPSC amplitudes at corresponding stimulus intensities. Inset, Traces show average waveforms for EPSC elicited by stimulus intensities of $9-18$ and 21-30 V.D,A 10 $\mathrm{Hz}$ stimulus train is delivered to the same cell in $\boldsymbol{C}$. After fatiguing the lower threshold input, a second large input is revealed when the stimulus was increased from 8 to 14 V. $\boldsymbol{E}$, Currents evoked using minimal stimulation protocol for all 29 MNTB cells. Cells are divided into three panels based on the minimal stimulation protocol applied to each cell (left, 2-20 V; middle, 3-30 V; right, 4-40 V). A particular protocol was chosen based on initial estimates of stimulus thresholds (see Materials and Methods). Average EPSC amplitudes ( $n=4$ stimuli per intensity) for each stimulus intensity are plotted for each cell. Colored triangles designate the four cells exhibiting innervation by multiple large inputs. Open triangles denote the lower threshold currents for each cell contacted by dual inputs. Traces of cells exhibiting single innervation are either black or gray to distinguish among the multiple traces. All recordings performed at -70 $\mathrm{mV}$ to isolate AMPA receptor-mediated currents.

inputs differed significantly $(p<0.00001)$. This amplitude criterion was used to classify calyceal inputs, regardless of whether cells were singly or dually innervated. Interestingly, the average individual EPSC amplitude for the dually innervated MNTB cells was noticeably less than that of the singly innervated cells [dual, $-1.37 \pm 0.16 \mathrm{nA}$ (range, -0.81 to $-2.15 \mathrm{nA}$ ); single, $-6.71 \pm$ $0.65 \mathrm{nA}$ (range, -0.92 to $-12.94 \mathrm{nA}$ )].

These examples of multiple innervation by two large inputs differ from the smaller inputs described earlier that we classified as noncalyceal. In a subset of cells, these smaller inputs had lower thresholds than the large calyceal inputs ( 10 cells) or much longer latencies (one cell), so their amplitudes and latencies could be quantified in relative isolation. For this group of 11 cells, calyceal EPSCs averaged $-5.73 \pm 0.91 \mathrm{nA}$ (range, -0.92 to $-10.42 \mathrm{nA}$ ). The small inputs averaged $-0.20 \pm 0.04 \mathrm{nA}$ (range, -0.067 to $-0.61 \mathrm{nA}$; although only one EPSC exceeded $-0.39 \mathrm{nA}$ ). Aside from its largest input, this group differed clearly from the inputs that we classified as calyceal, so the smaller inputs were classified as noncalyceal. Unlike the large dual inputs, the latencies of which were nearly identical, the latencies of the smaller inputs were always longer than the calyceal input onto the same cell (0.15-2.35 ms longer delay than the calyceal input). The largest of the small-amplitude inputs $(-0.61 \mathrm{nA})$ exhibited characteristics of the smaller calyceal input onto cells that were dually innervated. It was recorded from a cell that had a calyceal input $(-1.72$ $\mathrm{nA}$ ) near the bottom of the range of calyceal EPSC amplitudes, and the difference in latencies was small $(0.15 \mathrm{~ms})$. However, we categorized it as noncalyceal because it did not match the amplitude criterion of the large inputs. It is the only the small input that would have been considered calyceal in some studies (Forsythe and Barnes-Davies, 1993; Barnes-Davies and Forsythe, 1995; Bergsman et al. 2004), but note that other authors use $1 \mathrm{nA}$ as a criterion value (Futai et al., 2001).

\section{Three-dimensional reconstruction reveals few instances of multiple innervation at $\mathbf{P} 4$}

In a separate set of $\mathrm{P} 4$ tissue sections from the same animal used to quantify the prevalence of postsynaptic density and adherens junctions, we undertook a detailed examination of a large tissue area $(220 \times 130 \mu \mathrm{m}$ through 306 serial ultrathin sections encompassing a depth of $\sim 22 \mu \mathrm{m}$ ). Within this sample, we examined 52 MNTB cells and their associated inputs. Nine cells were completely contained, and another 10 cells were $>90 \%$ contained within these sections. These 19 cells formed the basis of our quantitative analyses (Table 2). We quantified terminal size by measuring the somatic surface area that they covered, as well as the surface area where somatic membrane was in direct apposition to the terminal membrane.

From this group of 19 cells, four neighboring cells, including cell bodies and proximal dendrites (colored tan), nuclei (colored red), and their associated inputs (colored light blue, green, yellow, purple, dark blue, and magenta), were chosen for threedimensional rendering of images from the serial sections (Figs. 7, 8; supplemental movie, available at www.jneurosci.org as supplemental material). These four cells demonstrate the diversity of MNTB neurons and large terminals observed within this sample. Two of the four cells (cells 3 and 15) were innervated by large cup-like young calyces (Fig. 7). The calyx onto cell 3 (light blue) measured $190.7 \mu \mathrm{m}^{2}$ and was the third largest terminal we encountered. The calyx onto cell 15 (green) measured $115 \mu \mathrm{m}^{2}$ and was the 15th largest terminal in our sample. This calyx extended a collateral (Fig. 7, green arrows) from the input onto cell 15 and formed a terminal onto cell 3 that measured $12.7 \mu \mathrm{m}^{2}$. This terminal size did not meet our criteria to be classified as a large input (see below). The other two reconstructed cells, cells 17 and 18 , were the only cells in our sample that were doubly innervated by large inputs (Fig. 8). All four of these double inputs were among the smallest in our sample, measuring between 22.6 and $76.9 \mu \mathrm{m}^{2}$. For both of these cells, the larger input was relatively unbranched and appeared similar in contour to the large inputs onto singly innervated cells.

The sizes of large terminals onto the 19 cells in our sample 
Table 2. Sizes of MNTB cells and large nerve terminals

\begin{tabular}{|c|c|c|c|c|c|c|}
\hline Cell & $\begin{array}{l}\text { Cell surface } \\
\text { area }\left(\mu \mathrm{m}^{2}\right)\end{array}$ & $\begin{array}{l}\text { Complete terminal } \\
\text { surface area }\left(\mu \mathrm{m}^{2}\right)\end{array}$ & $\begin{array}{l}\text { Apposed terminal } \\
\text { surface area }\left(\mu \mathrm{m}^{2}\right)\end{array}$ & $\begin{array}{l}\text { Apposed terminal/ } \\
\text { complete terminal }\end{array}$ & $\begin{array}{l}\text { Percentage of } \\
\text { somatic surface area } \\
\text { covered by terminal }\end{array}$ & $\begin{array}{l}\text { Percentage of } \\
\text { somatic surface area } \\
\text { apposed by terminal }\end{array}$ \\
\hline Cell $1^{a}$ & 660.8 & 271.4 & 230.4 & 0.85 & 41.1 & 34.9 \\
\hline Cell $2^{a}$ & 606.7 & 245.5 & 202.2 & 0.82 & 40.5 & 33.3 \\
\hline Cell 3 & 561.8 & 190.7 & 115.6 & 0.61 & 33.9 & 20.6 \\
\hline Cell $4^{a}$ & 531.9 & 173.5 & 147.3 & 0.85 & 32.6 & 27.7 \\
\hline Cell 5 & 601.3 & 164.1 & 144.4 & 0.88 & 27.3 & 24.0 \\
\hline Cell $6^{a}$ & 564.2 & 162.9 & 149.5 & 0.92 & 28.9 & 26.5 \\
\hline Cell 7 & 625.9 & 159.4 & 141.2 & 0.89 & 25.5 & 22.6 \\
\hline Cell $8^{a}$ & 568.7 & 157.4 & 149.4 & 0.95 & 27.7 & 26.3 \\
\hline Cell $9^{a}$ & 499.9 & 148.6 & 118.1 & 0.79 & 29.7 & 23.6 \\
\hline Cell 10 & 553.2 & 140.0 & 131.8 & 0.94 & 25.3 & 23.8 \\
\hline Cell 11 & 566.1 & 127.1 & 100.8 & 0.79 & 22.4 & 17.8 \\
\hline Cell $12^{a}$ & 517.3 & 126.6 & 102.9 & 0.81 & 24.5 & 19.9 \\
\hline Cell 13 & 577.9 & 125.8 & 109.2 & 0.87 & 21.8 & 18.9 \\
\hline Cell 14 & 553.6 & 123.9 & 96.7 & 0.78 & 22.4 & 17.5 \\
\hline Cell 15 & 495.6 & 115.0 & 67.2 & 0.58 & 23.2 & 13.6 \\
\hline Cell $16^{a}$ & 507.2 & 90.3 & 82.6 & 0.92 & 17.8 & 16.3 \\
\hline Cell 17 & 582.7 & $76.9,22.6$ & $62.1,17.4$ & $0.81,0.77$ & $13.2,3.9$ & $10.7,3.0$ \\
\hline Cell 18 ${ }^{a}$ & 619.7 & $71.4,39.4$ & $61.8,31.8$ & $0.87,0.81$ & $11.5,6.4$ & $10.0,5.1$ \\
\hline Cell 19 & 533.0 & 68.0 & 63.0 & 0.93 & 12.8 & 11.8 \\
\hline Average (all) & $564.6 \pm 10.3$ & $127.9 \pm 13.8$ & $106.3 \pm 11.8$ & $0.83 \pm 0.02$ & $22.5 \pm 2.3$ & $18.6 \pm 1.9$ \\
\hline Average (single input) & $560.3 \pm 11.0$ & $152.4 \pm 12.2$ & $126.6 \pm 10.6$ & $0.83 \pm 0.03$ & $26.9 \pm 1.8$ & $22.3 \pm 1.5$ \\
\hline Average (dual inputs) & $601.2 \pm 18.5$ & $52.6 \pm 13.0$ & $43.3 \pm 11.2$ & $0.85 \pm 0.04$ & $8.7 \pm 2.2$ & $7.2 \pm 1.9$ \\
\hline
\end{tabular}

Cells in three-dimensional reconstruction are highlighted in bold.

${ }^{a}$ Cell completely contained in sample; all others were $>90 \%$ complete.

range from 22.6 to $271.4 \mu \mathrm{m}^{2}$ (Table 2, column 3). This table does not include small terminals, such as those colored orange in Figures 7 and 8 . These small terminals were linked to fine processes that could not be traced unambiguously to other structures, such as calyces or large diameter axons. The sizes of the small orange inputs onto the four cells shown in Figures 7 and 8 averaged $1.6 \pm 0.3 \mu \mathrm{m}^{2}$ (range, 0.61-3.72 $\mu \mathrm{m}^{2} ; n=10$ ) and therefore constitute a distribution that is distinct from the large inputs. The calycine collateral on cell $3\left(12.7 \mu \mathrm{m}^{2}\right)$ (Fig. 7, green arrows) was closer in size to these small terminals than to larger inputs. On this basis, we considered only inputs larger than this calycine collateral to be indicative of protocalyces or young calyces. Therefore, using this criterion, most MNTB cells (17 of 19) are contacted by a single terminal. In the larger population of 52 neurons, we did not encounter cells that were not contacted by large terminals and therefore might be non-principal MNTB cells.

The complete terminal sizes listed above reflect measurements that would be made using light microscopy, which cannot distinguish the non-apposed from the apposed regions of the presynaptic terminal that have been described (Figs. 3-5). Electron microscopy affords the ability to make this distinction, and the terminal areas apposed to the postsynaptic cell are also listed in Table 2 (column 4). These values for protocalyces and young calyces range from 31.8 to $230.4 \mu \mathrm{m}^{2}$, reflecting the measurement that, on average, $84 \%$ of the nerve terminal is apposed to the postsynaptic cell (Table 2, column 4).

The size of terminals relative to the size of the postsynaptic cell may be an indicator of the synaptic strength of a particular input. We also measured somatic surface area from our electron micrographs and determined that this parameter can vary by a factor of 1.3 , from 496 to $661 \mu^{2}$. The ratio of apposed terminal to somatic surface area varied from 3 to $35 \%$ (Table 2 ). These values were larger, of course, when considering the complete terminal, and ranged from 4 to $41 \%$.

These large terminals appeared to have grown in a preferential direction, extending across the somatic surface from the location at which the axon approached the cell. None of the terminals shown in Figures 7 and 8 expanded over the nuclear pole of the cells. The young calyx on cell 3 was unusual in that it comprised two large pieces that were connected by a thin bridge (seen clearly in Fig. 7B). A solitary process (Fig. 7, blue arrowheads) extended from calyx 3 at the opposite end from the axon. This process appeared to continue the growth plan that directed expansion across the somatic surface, as noted by Morest (1968b) using Golgi-stained tissue. The solitary process may be an extension from the protocalyx and young calyx that is either a growing or retreating calycine collateral. Our observation that these processes are filled with vesicles of varying size (Fig. $3 F$ ) is consistent with both of these interpretations. The terminal on cell 15 also was cup-shaped and, like the terminal on cell 3 , had several thin processes leading out from the edge of the cup. However, one process lifted off the cell surface and extended to form the collateral terminal onto cell 3 (Fig. 7D, green arrows).

The direction of approach by calyx-forming axons to their targets was not consistent. The axons either tracked along a proximal dendrite before forming a calyx or made initial contact with the soma in an area essentially devoid of any dendrites. The axon leading to the young calyx onto cell 3 was traced back to a branch point within a trapezoid body fascicle (Fig. 7A). The calyxforming branch was similar in thickness to the main axon; the thinner branch projected transversely in the coronal plane of section and beyond the field of view of our tissue sections. Before making contact with cell 3, the calyx-forming branch curved around cell 15 in direct apposition with its somatic membrane, although no specialized contacts were observed. The axon leading into the large terminal onto cell 15 also had a thick caliber. The double inputs onto cells 17 and 18 were of relatively smaller caliber, corresponding to their relatively smaller terminal sizes. One of the inputs onto cell 17 (Fig. 8A-C, magenta; supplemental movie, available at www.jneurosci.org as supplemental material) 
appeared as a large en passant contact as the axon made a straight run through all of our sections without making contacts onto any additional cells (Fig. 8A-C; one or two asterisks are placed at each end of the axon). The two inputs onto cell 18 arrived from opposite directions (Fig. 8D-F, asterisks near yellow and purple inputs), increasing the likelihood that they were independent inputs. The axons of MNTB cells course together toward their synaptic targets in the lateral superior olive (Figs. 7, 8, ax).

\section{Structure-function correlations}

Because our ultrastructural reconstructions encompass an atypically large number of cells, we were able to compare features of our structural and functional measurements across similar sizes of cell populations (anatomical reconstructions of 19 cells; electrophysiology records from 29 cells). The amplitudes of AMPA receptor-mediated EPSCs and sizes of apposed nerve terminals are plotted in Figure 9 . We remind the reader that anatomical and physiological data were collected from different cells. The largest current amplitudes and terminal sizes correspond to values typical of $\sim 1$-week-old rodents (Taschenberger and von Gersdorff, 2000; Joshi and Wang, 2002) and may represent fully formed young calyces. The sizes of both current amplitudes and nerve terminals form a continuum, suggesting that calyx growth is ongoing at P4. Structural data indicate that each MNTB cell at P4 is contacted by at least one terminal that has reached the protocalyx stage. Note that the relatively few examples of dual inputs in both data sets rank near the bottom of their respective distributions (Fig. 9).

\section{Discussion}

We used electrophysiology and electron microscopy to assay the existence and extent of functional contacts onto MNTB neurons during formation of the calyx of Held. The ultrastructural analysis circumvented the limited spatial resolution of light microscopy and allowed us to tease out synaptic partners among tightly packed cells and dendrites in a complex neuropil. We analyzed atypically large populations of cells through serial ultrathin sections to provide quantitative information about the sizes of cells and presynaptic terminals as well as the number of inputs. Our principal results are as follows: (1) the amplitude of postsynaptic currents begins to increase at $\mathrm{P} 2$ and can rapidly reach values associated with young calyces within $48 \mathrm{~h}$; (2) concomitantly, calyx growth begins at $\mathrm{P} 2$ and proceeds rapidly, such that large terminals have reached the stage of young calyces or latestage protocalyces within the same time frame; and (3) relatively few cells at $\mathrm{P} 4$ are innervated by more than one large terminal.
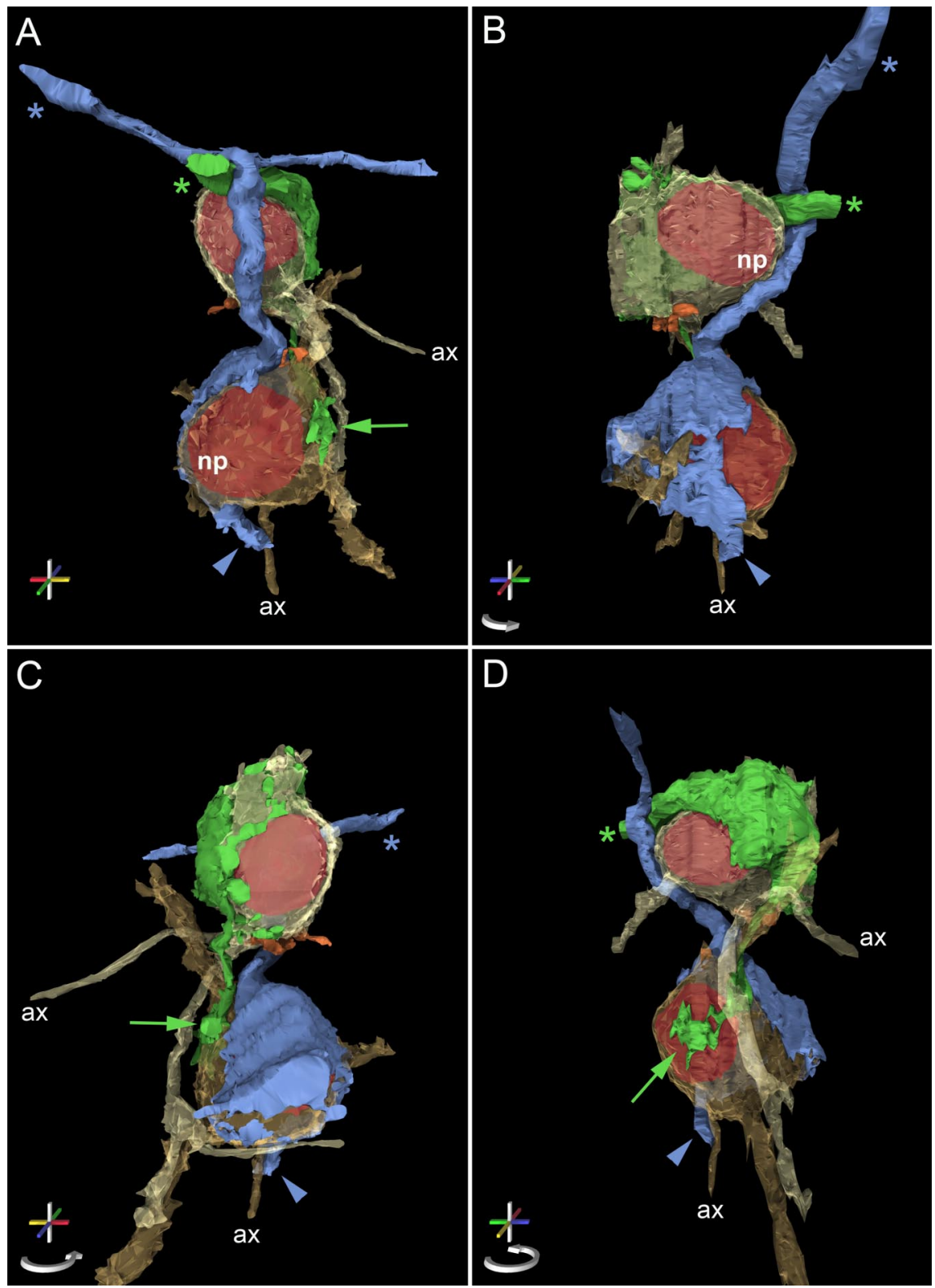

Figure 7. Three-dimensional reconstruction of two neighboring MNTB cells at P4. Four views of a pair of representative MNTB cells that were contacted by single large terminals are shown. $\boldsymbol{B}-\boldsymbol{D}$ are 90,180 , and $270^{\circ}$ clockwise rotations of $\boldsymbol{A}$ about the vertical axis. Rotated scale axes and arrows are provided for reference. MNTB cells are transparent and colored tan (top; cell 15 in Results and Table 2) or brown (bottom, cell 3) for distinction of overlapping dendrites and axons. (ell bodies are ovoid in shape and exhibit two to three dendrites (only proximal dendrites included in reconstruction) and an eccentric nucleus (red). The blue terminal consists of two large pieces linked by a narrow bridge $(\boldsymbol{B})$ and has a solitary process extending away from the cell body (blue arrowhead in all panels). The axon of this terminal was traced to its branch point in a trapezoid body fiber fascicle. The green terminal onto the top cell extends a collateral that contacts the bottom cell (green arrow; $\boldsymbol{A}, \boldsymbol{C}, \boldsymbol{D}$ ). Innervation territories avoided the nuclear pole (np) of the MNTB cells ( $\boldsymbol{B}$, top cell; $\boldsymbol{A}$, bottom cell). Orange terminals could not be linked through fine processes to other inputs onto the cell or to an axon. Asterisks indicate the axons for each terminal of the corresponding color. Scale axes: $2 \mu \mathrm{m}$ from origin to end, $4 \mu \mathrm{m}$ in diameter. Note that scale bars in the three-dimensional perspective views apply most accurately to the middle depth of field in Figures 7 and 8.

\section{Competition among large nerve terminals for postsynaptic targets is rare}

At P4, only two of 19 cells (11\%) reconstructed in three dimensions were contacted by more than one large nerve terminal. These anatomical counts could lead to an overestimate of convergence if converging terminals were branches with a union outside of the available sections; note that convergence of distant branches has been shown for calyceal axons of P9 rats (Rodriguez-Contreras et al., 2006). However, 4 of 29 cells (14\%) 

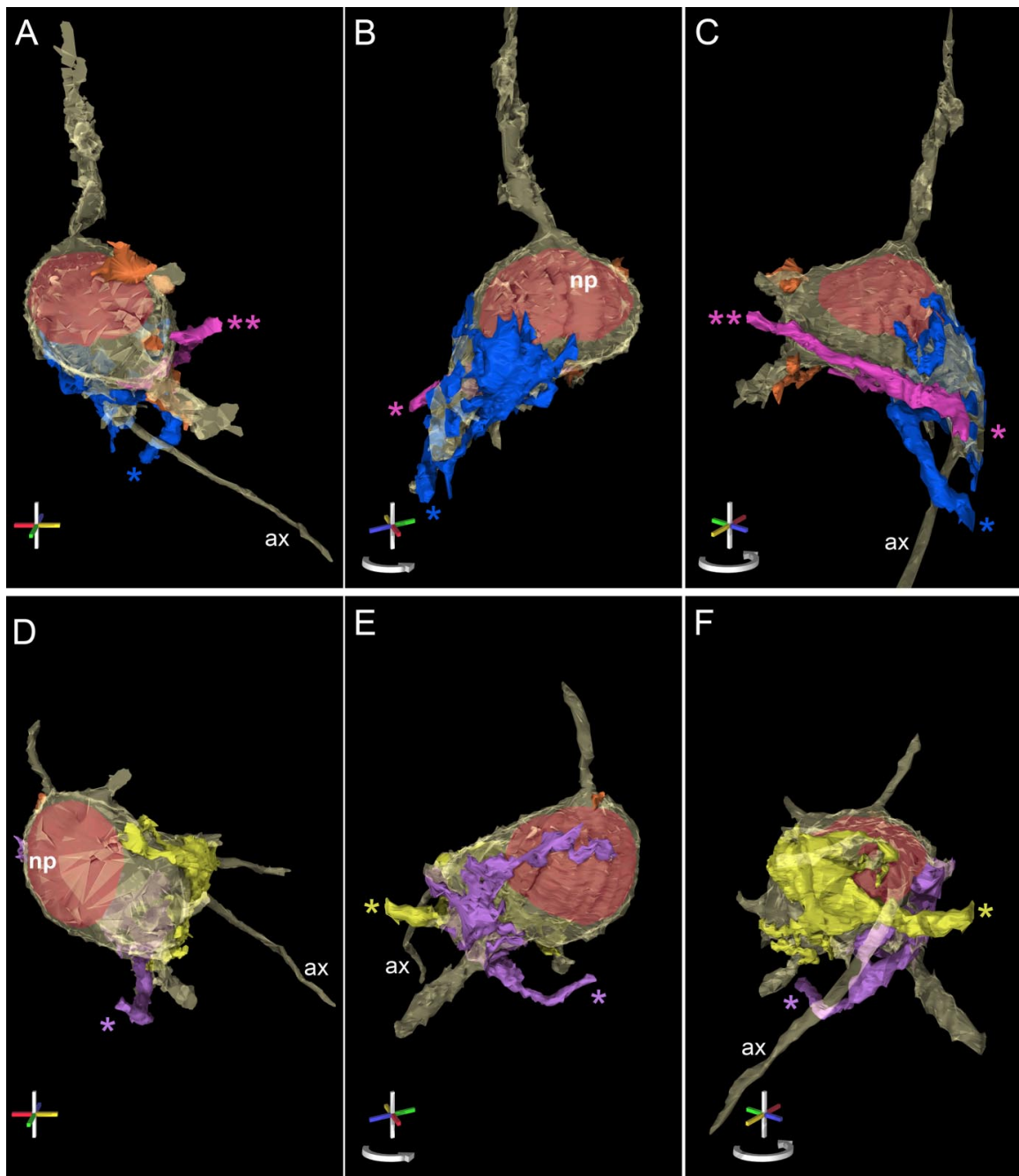

Figure 8. Three-dimensional reconstruction of two MNTB cells that are adjacent to cells depicted in Figure 7. $\boldsymbol{A}-\boldsymbol{C}$ and $\boldsymbol{D}-\boldsymbol{F}$ show two cells that were each contacted by two large terminals. $\boldsymbol{B}$ and $\boldsymbol{C}$ show 120 and $240^{\circ}$ clockwise rotations of $\boldsymbol{A}$ about the vertical axis; $\boldsymbol{E}$ and $\boldsymbol{F}$ are 120 and $240^{\circ}$ clockwise rotations of $\boldsymbol{C}$ about the vertical axis. Rotated scale axes and arrows are provided for reference. Cells depicted in $\boldsymbol{A}-\boldsymbol{C}$ and $\boldsymbol{D}-\boldsymbol{F}$ are referred to as cells 17 and $\mathbf{1 8}$, respectively, in Results and Table 2 . The larger input to each cell (dark blue input onto top cell; yellow input onto bottom cell) is more flattened and less branched than the smaller input (magenta input onto top cell; purple input onto bottom cell). Terminals do not contact the nuclear pole (np) of each cell $(\boldsymbol{B}, \boldsymbol{E})$. Small terminals (colored orange) could not be linked through fine processes to other inputs onto the cell or to an axon. Axons for each large terminal are marked by an asterisk of corresponding color. The magenta input onto the top cell delivered an en passant terminal. The different ends of this axon are denoted by one or two asterisks. Axons of other inputs are curved around, but not in contact with, the cell bodies. Axons (ax) from each MNTB cell course together (not shown in these isolated views) toward their postsynaptic targets in the lateral superior olive. Scale axes, $4 \mu \mathrm{m}$ (end to end).
A

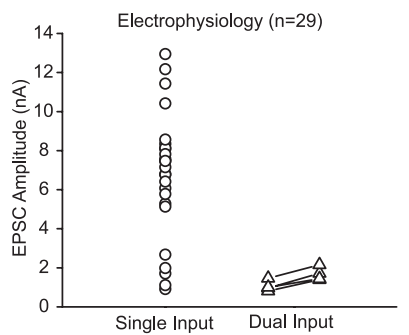

B

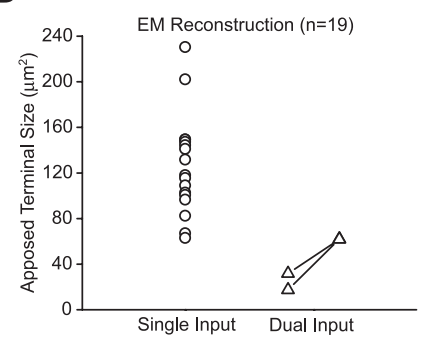

Figure 9. Comparison of nerve terminal size and EPSC amplitude at P4. A, EPSC amplitudes recorded from 29P4 MNTB cells. Each value is an average of at least eight traces per cell. Circles represent cells exhibiting single innervation, and paired triangles represent cells with physiological signatures of dual innervation. $\boldsymbol{B}$, Surface areas of terminals in apposition to $19 \mathrm{P} 4$ cells, measured from different cells than those shown in $\boldsymbol{A}$. Circles represent 17 cells with only one large terminal, and paired triangles represent cells contacted by two large terminals. EM, Electron microscopy. studied physiologically also exhibited the signature of multiple inputs. Both of these values are slightly larger than previous estimates, based on physiological techniques, that $7 \%$ of MNTB cells at P7-P13 are multiply innervated (Bergsman et al., 2004). Physiological techniques could yield underestimates of convergence because some inputs could be shaved during slice preparation, stimulating electrodes may not activate all inputs, or inputs with similar thresholds might not be distinguishable. Nonetheless, our data indicate that, when cells are preselected for recording based on the presence of $\mathrm{Ca}^{2+}$ signals, physiological estimates of multiple innervation correlate strongly with direct anatomical measurement. It appears, then, that mono-innervation is essentially established by P4, with the number of cells that are multi-innervated declining by nearly one-half by P7-P13.

Both our anatomical and physiological data sets at $\mathrm{P} 4$ were large enough to permit comparisons between them. Note that the terminal sizes and EPSC amplitudes for cells multiply innervated in both data sets fall at the bottom of their respective size distributions (Fig. 9). This observation may indicate that only a limited area of somatic membrane is available for innervation and must be shared by two smaller inputs. An alternative, but not exclusive, possibility is that competitive interactions occur between early protocalyces to sort out a winning input before the late protocalyx stage. Although it is tempting to speculate that the larger of the paired inputs represents the likely winner, elegant studies of the NMJ reveal that the smaller input can displace the larger input (Kasthuri and Lichtman, 2003; Walsh and Lichtman, 2003). In adult animals, each globular bushy cell, the calyx-forming cell type that is located in the cochlear nucleus, produces one or two calyces (Friauf and Ostwald, 1988; Spirou et al., 1990; Kuwabara et al., 1991; Smith et al., 1991), a much smaller number than the tens to hundreds of endings that form a motor unit (Bodine et al., 1987). However, it is unknown whether the number of globular bushy cell terminals is larger at early developmental stages or whether selection principles apply that are similar to those in effect at the NMJ (Kasthuri and Lichtman, 2003).

The origin of the small contacts was difficult to determine, because they emerged from very fine processes that could not be traced reliably through serial sections. It seems quite plausible that these small inputs are the anatomical correlates to the small amplitude EPSCs that we describe for P4 animals. The excitatory nature of these inputs is consistent with the hypothesis that they originate from globular bushy cells and therefore might correspond to the calycine and precalycine collaterals that persist into adulthood as small terminals (Tolbert and Morest, 1982; Kuwabara 
et al., 1991; Smith et al., 1991; Kandler and Friauf, 1993). It is noteworthy that all small noncalyceal EPSCs had longer latencies than the large calyceal EPSC(s), so it is less likely that some of these processes are branches from the calyx on the same cell, the thin connecting processes of which could not be tracked. Calycine collaterals can be large at this age, as illustrated in Figure 7, and these might correspond to the largest of the stimulus-evoked currents classified as noncalyceal.

Alternatively, it is possible that these small terminals represent early or late stages of competitive innervation or nonglobular bushy cell inputs that are possibly inhibitory. Note that the presence of round vesicles in all small terminals does not rule out a possible inhibitory function, because vesicle shape is a poor indicator of this functional parameter in neonatal animals (for review, see Vaughn, 1989). These small terminals did not exhibit degenerative profiles such as occurs in retraction bulbs at the NMJ (Bishop et al., 2004), suggesting that few, if any, are losers of a competitive interaction. For these terminals to increase in size after P4 and displace an existing large terminal does not seem to be an efficient use of cellular energy. Therefore, we consider it most likely that many of these terminals are calycine or precalycine collaterals.

\section{Calyx formation precedes auditory experience}

In the auditory system, machinery to transduce sound is present at neonatal ages. Significant neurotransmission can occur between hair cells and auditory nerve fibers at P6 but is minimal between P0 and P4 (Beutner and Moser, 2001). In mice, the earliest measurement of auditory nerve fiber-elicited synaptic transmission in the cochlear nucleus is $\mathrm{P} 4$ (Wu and Oertel, 1987). The age range that we studied precedes maturation of the inner ear and auditory nerve such that even internally generated sounds, including ultrasonic calls made by neonatal rat pups (Ehret, 2005), are unlikely to self-stimulate the auditory system. Airborne sounds do not evoke measurable physiological or behavioral responses in rodents until P8-P10 (Mikaelian and Ruben, 1965; Eggermont, 1985). Therefore, the establishment of calyceal mono-innervation occurs independent of experience, in contrast with other systems in which mono-innervation occurs via large nerve terminals, such as the NMJ and climbing fiber input to the Purkinje cell (Crepel et al., 1976; Jansen and Fladby, 1990; Balice-Gordon and Lichtman, 1993). In these systems, significant pruning of inputs occurs during the first 2-3 postnatal weeks as the animal expands its repertoire of voluntary motor activities.

Our data indicate that synapses formed onto MNTB neurons as early as P1 are functional. Although sound-evoked activity likely does not traverse the auditory system between P0 and P4, spontaneous activity may occur (Walsh and McGee, 1987). Spontaneous activity may play a role in establishing monoinnervation as well as in guiding the expansion of these large terminals via activation of NMDA receptors, the presence of which we have shown physiologically as early as $\mathrm{P} 1$. This receptor type, implicated in multiple aspects of brain plasticity, may trigger cellular events, such as the WNT signaling pathway that is important for mossy fiber terminal growth (Hall et al., 2000), that could activate calyx growth and mediate communication between presynaptic and postsynaptic partners.

\section{Directed growth of the calyx of Held}

We observed that protocalyces and young calyces expand over the cell surface but appear to exclude the nuclear pole, where the nuclear and cytoplasmic membranes are nearly apposed. This observation must be further evaluated but leads to the intriguing hypothesis that calyx growth is limited to only a portion of the surface of the MNTB cell, as proposed by Jhaveri and Morest (1982) for auditory nerve innervation of the chick nucleus magnocellularis. Insertion of postsynaptic densities (Skoff and Hamburger, 1974; Oppenheim et al., 1975; Vaughn, 1989) or the appearance of polarized flocculent cytoplasm (Jhaveri and Morest, 1982) before innervation has been documented in other systems. Although we did not observe either of these structural arrangements, it seems likely that signals originating from the MNTB cell, and not the calyx-forming axon, determine that a calyx terminal should develop. This notion (for review, see Rubel and Fritzsch, 2002) stems from the fact that individual globular bushy cells innervate multiple targets but only deliver calyces into the MNTB (Morest, 1968a; Friauf and Ostwald, 1988; Spirou et al., 1990; Smith et al., 1991).

Young calyces appear to grow unidirectionally from their point of contact onto the MNTB cell (Ramón y Cajal, 1909; Morest, 1968b; Kandler and Friauf, 1993; Kil et al., 1995). Our data show that late-stage protocalyx and young calyx geometry consists of a cup-shaped area with branch-like edges that can form small collateral inputs onto another cell (Fig. 7). These calycine collaterals have been well documented (Morest, 1968b; Kandler and Friauf, 1993; Kil et al., 1995) and may represent a second stage of multi-innervation that follows young calyx formation. These small collaterals do not appear capable of generating calyxlike synaptic currents and, as mentioned previously, only persist into adulthood as fine branches (Tolbert and Morest, 1982; Kuwabara et al., 1991; Smith et al., 1991; Kandler and Friauf, 1993).

In summary, we documented rapid growth of the first-formed calyces by $\mathrm{P} 4$. The presence of protocalyces at P4 indicates that calyx growth is still dynamic. Given their rate of expansion, young calyces are likely fully in place by P5. Investigations of competition in this system now shift to earlier ages. The compressed timescale for nerve terminal growth makes this system a good model to investigate synaptogenesis, and the large size of the terminal makes it attractive for combined cell biology, physiology, and molecular biology studies. Even in the relative absence of competitive interactions by the late stage of protocalyx formation, this system should prove useful to identify molecular signals that guide topographic and, specifically for the auditory system, tonotopic connections among neurons.

\section{References}

Aoki E, Semba R, Keino H, Kato K, Kashiwamata S (1988) Glycine-like immunoreactivity in the rat auditory pathway. Brain Res 442:63-71.

Balice-Gordon RJ, Lichtman JW (1993) In vivo observations of pre- and postsynaptic changes during the transition from multiple to single innervation at developing neuromuscular junctions. J Neurosci 13:834-855.

Barnes-Davies M, Forsythe ID (1995) Pre- and postsynaptic glutamate receptors at a giant excitatory synapse in rat auditory brainstem slices. J Physiol (Lond) 488:387-406.

Bergsman JB, De Camilli P, McCormick DA (2004) Multiple large inputs to principal cells in the mouse medial nucleus of the trapezoid body. J Neurophysiol 92:545-552.

Berrebi AS, Spirou GA (1998) PEP-19 immunoreactivity in the cochlear nucleus and superior olive of the cat. Neuroscience 83:535-554.

Beutner D, Moser T (2001) The presynaptic function of mouse cochlear inner hair cells during development of hearing. J Neurosci 21:4593-4599.

Billups B, Wong AY, Forsythe ID (2002) Detecting synaptic connections in the medial nucleus of the trapezoid body using calcium imaging. Pflügers Arch 444:663-669.

Bishop DL, Misgeld T, Walsh MK, Gan WB, Lichtman JW (2004) Axon branch removal at developing synapses by axosome shedding. Neuron 44:651-661. 
Bodine SC, Roy RR, Eldred E, Edgerton VR (1987) Maximal force as a function of anatomical features of motor units in the cat tibialis anterior. J Neurophysiol 57:1730-1745.

Campistron G, Buijs RM, Geffard M (1986) Glycine neurons in the brain and spinal cord. Antibody production and immunocytochemical localization. Brain Res 376:400-405.

Cant NB, Morest DK (1979) The bushy cells in the anteroventral cochlear nucleus of the cat. A study with the electron microscope. Neuroscience 4:1925-1945.

Cathala L, Holderith NB, Nusser Z, DiGregorio DA, Cull-Candy SG (2005) Changes in synaptic structure underlie the developmental speeding of AMPA receptor-mediated EPSCs. Nat Neurosci 8:1310-1318.

Crepel F, Mariani J, Delhaye-Bouchaud N (1976) Evidence for a multiple innervation of Purkinje cells by climbing fibers in the immature rat cerebellum. J Neurobiol 7:567-578.

Eggermont JJ (1985) Evoked potentials as indicators of auditory maturation. Acta Otolaryngol Suppl 421:41-47.

Ehret G (2005) Infant rodent ultrasounds-a gate to the understanding of sound communication. Behav Genet 35:19-29.

Forsythe ID, Barnes-Davies M (1993) The binaural auditory pathway: excitatory amino acid receptors mediate dual timecourse excitatory postsynaptic currents in the rat medial nucleus of the trapezoid body. Proc R Soc Lond B Biol Sci 251:151-157.

Friauf E, Ostwald J (1988) Divergent projections of physiologically characterized rat ventral cochlear nucleus neurons as shown by intra-axonal injection of horseradish peroxidase. Exp Brain Res 73:263-284.

Futai K, Okada M, Matsuyama K, Takahashi T (2001) High-fidelity transmission acquired via a developmental decrease in NMDA receptor expression at an auditory synapse. J Neurosci 21:3342-3349.

Hall AC, Lucas FR, Salinas PC (2000) Axonal remodeling and synaptic differentiation in the cerebellum is regulated by WNT-7a signaling. Cell 100:525-535.

Held H (1893) Die centrale Gehorleitung. Arch Anat Physiol Anat Abt 17:201-248.

Jackson H, Parks T (1982) Functional synapse elimination in the developing avian cochlear nucleus with simultaneous reduction in cochlear nerve axon branching. J Neurosci 2:1736-1743.

Jansen JK, Fladby T (1990) The perinatal reorganization of the innervation of skeletal muscle in mammals. Prog Neurobiol 34:39-90.

Jhaveri S, Morest DK (1982) Sequential alterations of neuronal architecture in nucleus magnocellularis of the developing chicken: an electron microscope study. Neuroscience 7:855-870.

Joshi I, Wang LY (2002) Developmental profiles of glutamate receptors and synaptic transmission at a single synapse in the mouse auditory brainstem. J Physiol (Lond) 540:861-873.

Kandler K, Friauf E (1993) Pre- and postnatal development of efferent connections of the cochlear nucleus in the rat. J Comp Neurol 328:161-184.

Kasthuri N, Lichtman JW (2003) The role of neuronal identity in synaptic competition 424:426-430.

Kil J, Kageyama GH, Semple MN, Kitzes LM (1995) Development of ventral cochlear nucleus projections to the superior olivary complex in gerbil. J Comp Neurol 353:317-340.

Kuwabara N, DiCaprio RA, Zook JM (1991) Afferents to the medial nucleus of the trapezoid body and their collateral projections. J Comp Neurol 314:684-706.

Lane BP, Eura DL (1965) Differential staining of ultrathin sections of Eponembedded tissues for light microscopy. J Histochem Cytochem 13:579-582.

Lichtman JW, Sanes JR (2003) Watching the neuromuscular junction. J Neurocytol 32:767-775.

Limb CJ, Ryugo DK (2000) Development of primary axosomatic endings in the anteroventral cochlear nucleus of mice. J Assoc Res Otolaryngol 1:103-119.

Mikaelian D, Ruben RJ (1965) Development of hearing in the normal CBA-J mouse. Acta Otolaryngol 59:451-461.

Morest DK (1968a) The collateral system of the medial nucleus of the trapezoid body of the cat, its neuronal architecture and relation to the olivocochlear bundle. Brain Res 9:288-311.

Morest DK (1968b) The growth of synaptic endings in the mammalian brain: a study of the calyces of the trapezoid body. Z Anat Entwicklungsgesch 127:201-220.
Oppenheim RW, Chu-Wang IW, Foelix RF (1975) Some aspects of synaptogenesis in the spinal cord of the chick embryo: a quantitative electron microscopic study. J Comp Neurol 161:383-418.

Peyret D, Campistron G, Geffard M, Aran JM (1987) Glycine immunoreactivity in the brainstem auditory and vestibular nuclei of the guinea pig. Acta Otolaryngol 104:71-76.

Ramón y Cajal S (1909) Histologie du Système Nerveux de l'Homme and des Vertébrés. Madrid: Instituto Ramón y Cajal.

Rodriguez-Contreras A, de Lange RP, Lucassen PJ, Borst JG (2006) Branching of calyceal afferents during postnatal development in the rat auditory brainstem. J Comp Neurol 496:214-228.

Rowland KC, Irby NK, Spirou GA (2000) Specialized synapse-associated structures within the calyx of Held. J Neurosci 20:9135-9144.

Rubel EW, Fritzsch B (2002) Auditory system development: primary auditory neurons and their targets. Annu Rev Neurosci 25:51-101.

Satzler K, Sohl LF, Bollmann JH, Borst JG, Frotscher M, Sakmann B, Lubke JH (2002) Three-dimensional reconstruction of a calyx of Held and its postsynaptic principal neuron in the medial nucleus of the trapezoid body. J Neurosci 22:10567-10579.

Shapira M, Zhai RG, Dresbach T, Bresler T, Torres VI, Gundelfinger ED, Ziv NE, Garner CC (2003) Unitary assembly of presynaptic active zones from Piccolo-Bassoon transport vesicles. Neuron 38:237-252.

Skoff RP, Hamburger V (1974) Fine structure of dendritic and axonal growth cones in embryonic chick spinal cord. J Comp Neurol 153:107-147.

Smith PH, Joris PX, Carney LH, Yin TC (1991) Projections of physiologically characterized globular bushy cell axons from the cochlear nucleus of the cat. J Comp Neurol 304:387-407.

Sommer I, Lingenhohl K, Friauf E (1993) Principal cells of the rat medial nucleus of the trapezoid body: an intracellular in vivo study of their physiology and morphology. Exp Brain Res 95:223-239.

Sotelo C (2004) Cellular and genetic regulation of the development of the cerebellar system. Prog Neurobiol 72:295-339.

Spirou GA, Berrebi AS (1997) Glycine immunoreactivity in the lateral nucleus of the trapezoid body of the cat. J Comp Neurol 383:473-488.

Spirou GA, Brownell WE, Zidanic M (1990) Recordings from cat trapezoid body and HRP labeling of globular bushy cell axons. J Neurophysiol 63:1169-1190.

Taschenberger H, von Gersdorff H (2000) Fine-tuning an auditory synapse for speed and fidelity: developmental changes in presynaptic waveform, EPSC kinetics, and synaptic plasticity. J Neurosci 20:9162-9173.

Taschenberger H, Leao RM, Rowland KC, Spirou GA, von Gersdorff $\mathrm{H}$ (2002) Optimizing synaptic architecture and efficiency for highfrequency transmission. Neuron 36:1127-1143.

Tolbert LP, Morest DK (1982) The neuronal architecture of the anteroventral cochlear nucleus of the cat in the region of the cochlear nerve root: electron microscopy. Neuroscience 7:3053-3067.

Tolbert LP, Morest DK, Yurgelun-Todd DA (1982) The neuronal architecture of the anteroventral cochlear nucleus of the cat in the region of the cochlear nerve root: horseradish peroxidase labelling of identified cell types. Neuroscience 7:3031-3052.

Vaughn JE (1989) Fine structure of synaptogenesis in the vertebrate central nervous system. Synapse 3:255-285.

Walsh EJ, McGee J (1987) Postnatal development of auditory nerve and cochlear nucleus neuronal responses in kittens. Hear Res 28:97-116.

Walsh MK, Lichtman JW (2003) In vivo time-lapse imaging of synaptic takeover associated with naturally occurring synapse elimination. Neuron 37:67-73

Warr WB (1972) Fiber degeneration following lesions in the multipolar and globular cell areas in the ventral cochlear nucleus of the cat. Brain Res 40:247-270.

Wimmer VC, Nevian T, Kuner T (2004) Targeted in vivo expression of proteins in the calyx of Held. Pflügers Arch 449:319-333.

Wu SH, Oertel D (1987) Maturation of synapses and electrical properties of cells in the cochlear nuclei. Hear Res 30:99-110.

Zhai RG, Vardinon-Friedman H, Cases-Langhoff C, Becker B, Gundelfinger ED, Ziv NE, Garner CC (2001) Assembling the presynaptic active zone: a characterization of an active zone precursor vesicle. Neuron 29: 131-143. 